\title{
Assembling Hollow Carbon Sphere-Graphene Polylithic Aerogels for Thermoelectric Cells
}

Dapeng Dong ${ }^{\mathrm{a}, \mathrm{b}}$, Haitao Guo ${ }^{\mathrm{a}}$, Guangyong Li ${ }^{\mathrm{a}}$, Lifeng Yan ${ }^{\mathrm{c}}$, Xuetong Zhang ${ }^{\mathrm{a}, *}$, Wenhui Song ${ }^{\mathrm{d}, *}$

${ }^{a}$ Suzhou Institute of Nano-Tech and Nano-Bionics, Chinese Academy of Sciences, Suzhou, 215123, P. R. China

${ }^{\mathrm{b}}$ Nano Science and Technology Institute, University of Science and Technology of China, Suzhou 215123, P. R. China

${ }^{c}$ Department of Chemical Physics, University of Science and Technology of China, Hefei, 230026, P. R. China

${ }^{\mathrm{d}}$ Center for Nanotechnology and Regenerative Medicine, Division of Surgery and Interventional Science, University College London, London, NW3 2PF, United Kingdom

E-mail:w.song@ucl.ac.uk

xtzhang2013@sinano.ac.cn

D. Dong and H. Guo were contributed equally to this work 


\begin{abstract}
Aerogels are highly porous bulk materials assembled chemically or physically with various nanoscale building blocks and thus hold promise for numerous applications including energy storage and conversion. Assembling of hollow or porous particles with the diameter larger than $100 \mathrm{~nm}$ into hierarchically porous aerogels is efficient but challenging for achieving a high specific surface of aerogel. In this regard, submicron-sized carbon spheres with hollow cores and microporous shells are assembled into bulk aerogels, for the first time, in the presence of twodimensional graphene sheets as special cross-linkers. The resulting bead-to-sheet polylithic aerogels show ultra-low density $\left(51-67 \mathrm{mg} \cdot \mathrm{cm}^{-3}\right)$, high conductivity $\left(263-695 \mathrm{~S} \cdot \mathrm{m}^{-1}\right)$ and high specific surface area $\left(569-609 \mathrm{~m}^{2} \cdot \mathrm{g}^{-1}\right)$. An application of thermocells is demonstrated with maximum output power of $1.05 \mathrm{~W} \cdot \mathrm{m}^{-2}$ and maximum energy conversion efficiency of $1.4 \%$ relative to Carnot engine, outperforming the current simple U-shaped thermocells reported elsewhere.
\end{abstract}




\section{Introduction}

Gradual exhaustion of fossil fuels and rapid increase of energy demand may cause a serious energy crisis in the very near future [1]. Either exploiting the new energy options or developing energy recycling is a highly efficient way to overcome increasingly grim energy crisis [2-6]. However, both technologies face the challenge of finding and integrating new materials to meet the demanding performance $[7,8]$. This constantly motivates scientists to develop novel energy materials [9-12].

An aerogel is a kind of highly porous nanomaterial [13] with many intriguing properties such as the high specific surface area (more than several hundred $\mathrm{m}^{2} \cdot \mathrm{g}^{-1}$ ), ultra-low density (as low as $3 \mathrm{mg} \cdot \mathrm{cm}^{-3}$ ), large pore volume (several $\mathrm{cm}^{3} \cdot \mathrm{g}^{-1}$ ), low dielectric constant (approaching that of air), superior thermal-insulating behavior $\left(<0.015 \mathrm{~W} \cdot \mathrm{m}^{-1} \cdot \mathrm{K}^{-1}\right)$, outstanding sound-proofing property $\left(>100 \mathrm{~kg} \cdot \mathrm{m}^{-2} \cdot \mathrm{s}^{-1}\right)$, etc. $[14,15]$. In recent years, intensive studies and exploitations have been carried out across many fields including environmental remediation, thermal insulation, energy storage and conversion, detection, adsorption, catalysis, and so on [16-18]. From the perspective of chemistry, aerogels are the sol-gel derivatives made via supercritical fluid drying (or other special drying) of various gel precursors, while from the perspective of structure, aerogels are the three-dimensional (3D) interconnected open-packed assemblies of various nano-sized building blocks [19]. 0D nanoparticles (e.g. in quantum dot aerogel[20]), 1D nanofibers (e.g. in carbon nanotube aerogel [21]) and 2D nanosheets (e.g. in graphene aerogel [22]) have been assembled respectively into corresponding $3 \mathrm{D}$ aerogel monoliths via covalent bonding (or non-covalent bonding such as electrostatic interaction, hydrogen bonding, hydrophobic effect, $\pi-\pi$ stacking, van der Waals force, etc.) together with special drying techniques. Synthesis of various novel nano- 
sized building blocks and subsequent assembling into 3D bulk materials are at the cutting edge of the nanoscience and nanotechnology [23].

Multiple variables, such as shape, size, density, surface morphology, chemical attributes, etc. of the building blocks play important roles in determining structure and function of the resulting aerogel monoliths [24]. In the case of aerogels assembled with spherical particles, the specific surface area is inversely proportional to both the diameter and density of the individual solid particles under the assumption of no surface overlapping of the particles as shown in Figure 1a. It is desirable to obtain large specific areas of the aerogel with small diameter and/or low density particles [25]. However, only a small range of diameters of the building blocks, from a few to several tens of nanometers is particularly of interest for an aerogel as its specific area decreases substantially when the diameter of the solid spherical particles is larger than $100 \mathrm{~nm}$ (Figure 1a). For example, polyaniline with the density of $1.36 \mathrm{~g} \cdot \mathrm{cm}^{-3}$ (the lightest shown in Figure 1a) and particle size of $100 \mathrm{~nm}$ has an aerogel monolith which only possess maximum specific surface area of less than $44 \mathrm{~m}^{2} \cdot \mathrm{g}^{-1}$. Such monoliths have lost the unique high-specific-surface-area property of the aerogels.

On the other hand, assembling particles with a high porosity (i.e. weight-lightening) can also achieve the aerogel with a high specific area. For each chosen material with its bulk density as a constant, creation of hollow or porous structure within the particles can substantially reduce the apparent density [26]. Therefore, assembling those hollow or porous particles will generate a hierarchically porous structure in combination with nano to micro voids. Small sized (e.g. several nm) particles are prone to be assembled via wet chemistry approaches [27]. However, assembling relatively larger particles, like hollow or porous spheres, with the diameter larger than $100 \mathrm{~nm}$ is not trivial (except close-packed photonic crystals [28]) due to much smaller inter-particle contact 
area (see Figure 1b) and thus far fewer reaction sites in comparison with those with diameters smaller than $100 \mathrm{~nm}$ [29]. Furthermore, assembling heterogeneously structured aerogels using particles with different size, shape and composition is an effective approach to achieve multifunctionality of an aerogel $[17,18]$. Despite more variables being involved, the above limitations related to competing dimension scales of the building blocks are fundamentally the same. No matter which type of aerogel is made, it is challenging to produce high performance aerogels consisting of hollow or porous building blocks with the diameter larger than $100 \mathrm{~nm}$.

Herein we report an ingenious strategy to assemble carbon hollow spheres using graphene as a nano-crosslinking agent to produce unique bead-to-sheet polylithic aerogels. An ultra lightweight carbon sphere structure with hollow core and microporous shell was designed and fabricated through carbonization of the model spherical particles made from conjugated polymeric hollow spheres (PHS) with the diameter up to $220 \mathrm{~nm}$. In order to increase the inter-particle contact area without weight penalty, graphene oxide (GO) sheets, the thinnest carbon oxide, were used to crosslink these conjugated polymer spheres as shown in Figure 1c. The resulting graphenecrosslinked hollow carbon sphere (GHCS) aerogels with low density $\left(51-67 \mathrm{mg} \cdot \mathrm{cm}^{-3}\right)$, high conductivity $\left(263-695 \mathrm{~S} \cdot \mathrm{m}^{-1}\right)$ and high specific surface area $\left(569-609 \mathrm{~m}^{2} \cdot \mathrm{g}^{-1}\right)$ have been obtained after in situ reductive assembly, supercritical $\mathrm{CO}_{2}$ extraction and inert atmosphere carbonization in sequence. High conductivity and porous structure have made the resulting aerogels ideal electrode materials for thermal electrochemical cells with output power of $1.05 \mathrm{~W} \cdot \mathrm{m}^{-2}$ and energy conversion efficiency of $1.4 \%$ relative to Carnot engine. The work presented here, to the best of our knowledge, is the first report on the fabrication of hollow sphere aerogels. The proven principle of this work has shed light on the design and assembly of various spherical building blocks with size much larger than $100 \mathrm{~nm}$ via linking or crosslinking with various $2 \mathrm{D}$ nanostructures. The 
obtained polylithic aerogels are promising for a diverse range of applications including energy storage and conversion due to their ultra-fine hierarchically porous structure and outstanding conductivity.

\section{Materials and Methods}

\subsection{Synthesis of graphene-crosslinked hollow carbon sphere (GHCS) aerogels}

Graphite (crystalline powder, 400 mesh), phosphorus pentoxide $\left(\mathrm{P}_{2} \mathrm{O}_{5}\right)$, potassium permanganate $\left(\mathrm{KMnO}_{4}\right)$, hydrogen peroxide $\left(\mathrm{H}_{2} \mathrm{O}_{2}\right)$, aniline $\left(\mathrm{C}_{6} \mathrm{H}_{7} \mathrm{~N}\right)$, pyrrole $\left(\mathrm{C}_{4} \mathrm{H}_{5} \mathrm{~N}\right)$, sulfuric acid $\left(\mathrm{H}_{2} \mathrm{SO}_{4}\right)$, ascorbic acid (VC) and ammonium persulfate (APS) were purchased from Sinopharm Chemical Reagent Company. Triton X-100 (TX-100) was purchased from Beijing Chemical Works. Aniline and pyrrole were distilled under reduced pressure before use. The rest of chemicals were used without further purification. Details of the synthesis of graphene oxide (GO) and poly(aniline-copyrrole) can be found in the Supplementary Information.

Graphene-linked hollow carbon sphere aerogels were synthesized according to the following procedure: First of all, $45 \mathrm{mg} \cdot \mathrm{mL}^{-1}$ poly(aniline-co-pyrrole) hollow spheres suspension was added into $8 \mathrm{mg} \cdot \mathrm{mL}^{-1} \mathrm{GO}$ suspension and then ultrasonicated for $30 \mathrm{~min}$ to obtain a homogeneous dispersion. Then, a certain amount of VC was added into above dispersion. The mass ratio of VC to $\mathrm{GO}$ is fixed to $5.0 \mathrm{in}$ all formulas (see Table $\mathbf{1}$ ). The reduction reaction took place under $60{ }^{\circ} \mathrm{C}$ without stirring for 12 hours to obtain a composite hydrogel. Secondly, the composite hydrogel was washed with ethanol via solvent exchange to remove various impurities, and then supercritical $\mathrm{CO}_{2}$ drying was applied to obtain corresponding aerogel. The yield of composite aerogel is $68.3 \%$. Finally, the above composite aerogel was placed into a tube furnace, heated to $900{ }^{\circ} \mathrm{C}$ with a heating rate of $10^{\circ} \mathrm{C} \cdot \mathrm{min}^{-1} \min$ under an argon flow $\left(200 \mathrm{~cm}^{3} \cdot \mathrm{min}^{-1}\right)$ and carbonized for 10 hours 
to obtain graphene-linked hollow carbon sphere aerogel. The yield from composite aerogel to graphene-linked hollow carbon sphere aerogel is $32.7 \%$. The total yield of the graphene-linked hollow carbon sphere aerogel is $22.3 \%$. The resulting aerogels are named GHCSA X-Z where GHCSA is the abbreviation of the graphene-linked hollow carbon sphere aerogel, $\mathrm{X}$ is the theoretical Density of the aerogel and $\mathrm{Z}$ is the mass ratio of PHS to GO in the synthetic formulas.

\subsection{Characterization and measurements}

The morphology of the samples was characterized by scanning electron microscope (SEM) (S4800) operated at $10 \mathrm{kV}$ and transmission electron microscope (TEM, Tecnai G2 F20 S-Twin) operated at $200 \mathrm{KV}$. The pore structure of the aerogels was investigated using a Surface Area Analyzer (Micrometrics, ASAP 2020 HD88). The Brunauer-Emmett-Teller (BET) method and the Barrett-Joyner-Halenda (BJH) model were utilized to calculate the BET specific surface area (SSA) and the pore size distribution. The crystal structure of the as-prepared samples was investigated by X-Ray Diffraction (XRD, D8 advance, Bruker AXS). Raman spectra were recorded using a LabRAM HR Raman Spectrometer (LabRAM HR, Horiba-JY) fitted with a 632.8 nm laser. The compressive stress-strain measurements were performed on an Instron 3365 tensile testing machine at a crosshead speed of $2 \mathrm{~mm} \cdot \mathrm{min}^{-1}$. Electrical conductivity of the samples with rectangle length and width of not less than $20 \mathrm{~mm}$ were measured by digital multi-function fourprobe tester (Suzhou Jingge Electronic Co., LTD, ST-2258A). The electrochemical performances were measured by electrochemical workstation (Wuhan Corrtest Instruments Co., Ltd. Wuhan, CS120) with a three-electrode configuration. A piece of aerogel sample (diameter $7.1 \mathrm{~mm}$ ) was directly pressed into the nickel foam with the load of $7 \mathrm{MPa}$ to serve as the working electrode, a platinum wire was used the counter electrode, saturated calomel electrode is used as the reference electrode and $0.1 \mathrm{M} \mathrm{NaCl}$ solution containing $0.01 \mathrm{M}$ ferro/ferricyanide solution was used as the 
supporting electrolyte. Electrochemical impedance measurements were conducted in the frequency range between $10 \mathrm{kHz}$ and $50 \mathrm{mHz}$ using a commercial instrument (Dual Electrochemical workstation, ZIVE BP2). $0.4 \mathrm{M} \mathrm{K}_{3}\left[\mathrm{Fe}(\mathrm{CN})_{6}\right] / \mathrm{K}_{3}\left[\mathrm{Fe}(\mathrm{CN})_{6}\right]$ solution was used as electrolyte. Platinum and $\mathrm{Ag} / \mathrm{AgCl}$ electrodes were used as counter and reference electrodes for the electrochemical impedance measurements. A homemade electro-thermal cell was set up to evaluate the electro-thermal performance. Aerogel samples directly pressed into the nickel foam with the load of $7 \mathrm{MPa}$ were used as the working electrode and counter electrode, respectively, 0.4 $\mathrm{M} \mathrm{K} \mathrm{K}_{3}\left[\mathrm{Fe}(\mathrm{CN})_{6}\right] / \mathrm{K}_{3}\left[\mathrm{Fe}(\mathrm{CN})_{6}\right]$ was used as the supporting electrolyte, heat band (Omega Engineering China, FGR-030/240V) and circulating water were used to keep the temperature difference. Thermocouple (Fluke, 54ПВ thermometer) was used to monitor the temperature of each electrode.

\section{Results and discussion}

\subsection{Materials synthesis and characterization}

Schematic synthesis of the GHCS-aerogels was depicted in Figure 1d. Conjugated polymer hollow spheres were synthesized via soft template approach reported in the literature [30]. FTIR spectrum indicated that aniline and pyrrole were co-polymerized in soft templates (see Supplementary Figure S1). Scanning Electron Microscopy (SEM) was used to confirm uniform spherical morphology of the product, and to measure the diameter of these spheres in the range of 150 to 220 nm (see Figure S2). Transmission Electron Microscopy (TEM) revealed the hollow structure of these conjugated co-polymer spheres (see Figure S3). A large number of micropores formed within the shell layers after carbonization of the hollow conjugated polymer spheres, which was confirmed via $\mathrm{N}_{2}$ sorption investigation (see Figure S4). Graphene oxide sheets were initially 
used as a surfactant to disperse and stabilize the submicron spheres due to their amphiphilicity and subsequently acted as crosslinker to connect these spheres due to strong $\pi-\pi$ interaction between graphene oxide sheets and conjugated polymers [31]. Vitamin C (VC) was used as reducing agent to trigger the gelation of the aqueous mixture of the graphene oxide sheets and polymeric spheres under $60{ }^{\circ} \mathrm{C}$ (see Figure S5). The gelatinized mixture was aged for 12 hours, solvent-exchanged with ethanol for 5 times, supercritically dried with $\mathrm{CO}_{2}$, and finally heat treated at $900{ }^{\circ} \mathrm{C}$ (the optimal carbonization temperature, see Figure S6) in argon for 10 hours to obtain polylithic aerogel. (Details see Experimental Section).

The resulting polylithic aerogel cylindrical rod with the volume of $\mathrm{ca} .1 .0 \mathrm{~cm}^{3}$ could stand on the flower stamens without causing bending as shown in Figure 2a, indicating ultra-light attribute of the product. The apparent density of the aerogel was tested in the range of $51-67 \mathrm{mg} \cdot \mathrm{cm}^{-3}$, varying with the reactant concentration and processing conditions (see Table 1-3). The morphological image by SEM in Figure $\mathbf{2 b}$ shows that the aerogel was solid-void phase-separated, which was induced by the well-known solute-solvent phase separation during sol-gel process. In the solid network, close and uniform packing between spherical particles with the diameter of ca. $110 \mathrm{~nm}$ and thin sheets with the thickness in the range of several nm could be clearly seen. It could be deduced that the former might be carbon spheres derived from the carbonization of the conjugated polymer spheres and the latter might be a few-layered graphene sheets derived from the carbonization of the graphene oxide sheets. It is noteworthy that most carbon spheres were attached to thin graphene sheets with very few direct inter-sphere aggragates. In comparison with the spheres before and after carbonization, a contraction of spheres was measured up to $30 \%$, resulting from the thermal annealing process. The crystallization of the aerogel in evidence of sharper (002) diffraction peak and reduction in its corresponding interplanar distance from 0.366 
$\mathrm{nm}$ to $0.35 \mathrm{~nm}$, revealed by X-ray diffraction patterns (see Figure S7), indicate denser packing of the aerogel after carbonization. More intriguingly, the TEM image in Figure 2c manifests the bead-sheet packing structure of the polylithic aerogel in great detail, in that the more or less monodispersed hollow structure of the carbon spheres remains, with shell thickness of ca. $30 \mathrm{~nm}$ and diameter of $110 \mathrm{~nm}$. Solid-void phase separation was observed more clearly with the hollow spherical particles embedded or wrapped by a few layered graphene sheets in the solid networks. Individual carbon spheres or graphene sheet aggregates were hardly observed, indicating that the graphene oxide sheets must have been dispersed uniformly in the precursor solution and there was a strong interaction between graphene sheets and carbon spheres (as well as between graphene oxide sheets and conjugated polymer spheres).

The $\pi-\pi$ stacking interaction between different components was studied and analyzed by Raman spectroscopy (see Figure S8). This strong interaction provided not only the main driving force for solution assembly of graphene-linked submicron sphere aerogels, but also contributed to the excellent properties of the final product for a broad range of applications. For example, the GHCS-aerogels have showed good mechanical behavior (Young's modulus of $1.8 \mathrm{MPa}$, yield strength of 0.4 MPa, see Figure S9) and excellent electrical performance (conductivity up to 695 $\left.\mathrm{S} \cdot \mathrm{m}^{-1}\right)$. The mechanical properties of the resulting aerogels are comparable to those of solution processed graphene aerogels [32], and even much higher than those of electrostatically assembled carbon nanotube aerogels [33]. The electrical conductivity of the resulting aerogel is 6 times higher than that of solution processed graphene aerogels [34], thousand folds higher than that of wetchemistry assembled carbon nanotube aerogels [35].

The hierarchical porous structure of the GHCS-aerogels was investigated by nitrogen sorption tests as shown in Figure 2d. A very high nitrogen uptake at low relative pressure $\left(\mathrm{P} / \mathrm{P}_{0}<0.02\right)$ 
demonstrated the existence of tremendous micropores in the aerogels. Contrast tests (see Figure S10) showed that these micropores are mainly located in the shell layer of the hollow carbon spheres. The $\mathrm{N}_{2}$ adsorption isotherm with type IV was observed, which is attributed to monolayer - multilayer adsorption and suggested mesoporous nature of the resulting aerogel [36]. The $\mathrm{N}_{2}$ adsorption-desorption isotherm exhibited a hysteresis loop with the character of $\mathrm{H} 3$, indicating the presence of slit-like pores [37]. The pore-size distribution plot was calculated using the BarrettJoyner-Halenda (BJH) method from the desorption branch of the isotherm, which revealed that pore diameters were mainly located at $0.5,4$ and $24 \mathrm{~nm}$, proving existence of both micropores (diameter $<2 \mathrm{~nm}$ ) and mesopores $(2 \mathrm{~nm}<$ diameter $<50 \mathrm{~nm})$ in the resulting graphene-linked hollow carbon sphere aerogel. The Brunauer - Emmett - Teller (BET) specific surface of the obtained aerogel was $609 \mathrm{~m}^{2} \cdot \mathrm{g}^{-1}$ (when the original mass ratio of graphene oxide to polymer sphere was set to 1:1) and decreased with an increase in hollow carbon sphere content (Table 1 and 2). This was attributed to the BET specific area of graphene sheets [38] $\left(2630 \mathrm{~m}^{2} \cdot \mathrm{g}^{-1}\right)$, which is much higher than that of hollow carbon spheres $\left(373 \mathrm{~m}^{2} \cdot \mathrm{g}^{-1}\right)$ after carbonizing of its corresponding precursors. Although submicron hollow carbon spheres are relatively large, the controllable BET specific surface area of the polylithic aerogel is, in fact, higher than 0D silica aerogel [15] (500 $\left.\mathrm{m}^{2} \cdot \mathrm{g}^{-1}\right), 1 \mathrm{D}$ cellulose nanofiber aerogel [39] $\left(290 \mathrm{~m}^{2} \cdot \mathrm{g}^{-1}\right)$, and even 2D boron nitride aerogel [40] $\left(275 \mathrm{~m}^{2} \cdot \mathrm{g}^{-1}\right)$. These results have demonstrated the feasibility and efficiency of assembling large submicron hollow or porous submicron particles by taking advantage of their low apparent density. Due to ultra-low density, large specific surface area, high electrical conductivity and good mechanical attribute, it is envisaged that the GHCS-aerogel could be applied in many fields including energy (harvesting, storage and conversion), sensors, catalysis, adsorption, separation, 
functional composites, etc. Herein we demonstrate its application in harvesting waste heat with subsequent heat-to-electricity conversion.

\subsection{Thermoelectric Cells}

A thermocell (also known as thermoelectric cell or thermo-galvanic cell) is a device that can utilize the temperature dependence of electrochemical redox potentials to produce electrical power, and thus can be used to harvest waste heat with simple design, direct thermal-to-electric energy conversion, continuous operation, expected low maintenance and zero carbon emission [41]. Both cell structure and electrode configuration have played significant roles in determining the performance of the resulting thermocells $[42,43]$. For simplicity, a U-shaped thermocell (as shown in Figure 3c) was installed with $\mathrm{Fe}(\mathrm{CN})_{6}{ }^{4-} / \mathrm{Fe}(\mathrm{CN})_{6}{ }^{3-}$ as a redox couple and GHCS-aerogel as an active electrode material. To understand the real electro-active surface area (ESA) of the aerogel working electrode, a traditional 3-electrode electro-chemical system (as shown in Figure 3a) with the same redox couple was initially set up and the corresponding cyclic voltammetry $(\mathrm{CV})$ curves were recorded and shown in Figure 3b. Obviously, redox peaks were observed in the potential range from -0.20 to $0.50 \mathrm{~V}$, indicating that all working electrode materials were redox-active $[44,45]$. The faradaic peak current of the graphene-linked hollow carbon sphere aerogels is higher than that of graphene aerogel and that of hollow carbon sphere, indicating best electrochemical behavior among these electrode materials [46]. The ESA could be derived from the Randles Sevcik equation [47] given by:

$\mathrm{I}_{\mathrm{p}}=2.69 \times 10^{5} \times \mathrm{ESA} \times \mathrm{D}^{1 / 2} \times \mathrm{n}^{3 / 2} \times v^{1 / 2} \times \mathrm{C}$

where $I_{p}$ is the faradaic peak current, $D$ is the diffusion coefficient, $n$ is the number of electrons transferred during the redox reaction, $v$ is the potential scan rate, and $C$ is the concentration of 
probe molecule. Analysis of the CV curve using the equation (1) showed that the GHCS-aerogel electrode possessed a higher ESA (see Figure S11), which may ascribe to both hollow core, and microporous shell of the submicron-sized spherical building blocks as well as the large surface of 2D graphene. In addition, the potential difference between oxidation and reduction peak may provide qualitative insight into the kinetics of electron transfer process [48]. Hence, the kinetics can be analyzed qualitatively using the difference of the potential peaks where sluggish kinetics will need more voltage or time to reach the peak current or the current where depletion of ions at the surface commences [49]. The potential difference of the GHCS-aerogel $(0.109 \mathrm{~V})$ is much smaller than that of hollow carbon spheres $(0.132 \mathrm{~V})$ and is similar to that of graphene aerogel $(0.111 \mathrm{~V})$, implying that electrodes with open-packed polylithic aerogel structure possessed the fastest electron transfer kinetics. Furthermore, the onset of the $\mathrm{Fe}(\mathrm{CN})_{6}{ }^{4-}$ oxide peak at the graphene-linked hollow carbon sphere aerogel electrode exhibited a significant negative potential shift (0.04 V towards graphene aerogel and $0.01 \mathrm{~V}$ towards hollow carbon sphere, respectively). This indicates significant catalytic behavior [50,51] of the GHCSA aerogel for $\mathrm{Fe}(\mathrm{CN})_{6}{ }^{4-} / \mathrm{Fe}(\mathrm{CN})_{6}{ }^{3-}$ redox couple, which may be attributed to doping of nitrogen atoms derived from conjugated polymer precursors [30] into microporous shells of carbon spheres within aerogel matrix (See Figure S12).

The open-circuit potential of the U-shaped thermocell was linearly proportional to the interelectrode temperature difference as shown in Figure 3d. The slope of the temperature difference versus potential curve is the Seeback coefficient as expressed below:

$\mathrm{S}=\partial v / \partial \mathrm{T}=\Delta \mathrm{S}_{\mathrm{B}, \mathrm{A}} / \mathrm{nF}$

where $T$ is the temperature, $v$ is the electrode potential, $n$ is the number of electrons involved in the reaction, $F$ is the Faraday's constant, $\Delta S_{B, A}$ is the reaction entropy for the redox couple. The 
Seebeck coefficient measured through U-shape thermoelectric cell was $1.43 \mathrm{mV} / \mathrm{K}$ (Figure 3d), in good agreement with previous reports $[47,52]$. The performance of the thermocell was mainly evaluated by the following two key parameters: the maximum output power $\left(\mathrm{P}_{\max }\right)$ and the relative power conversion efficiency $\left(\eta_{r}\right)$. The $P_{\max }$ was calculated through $0.25 V_{o c} \times I_{s c}$ and the $\eta_{r}$ was described as below:

$\eta=P_{\max } /(\operatorname{Ak}(\Delta \mathrm{T} / \mathrm{d}))$

$\eta_{\mathrm{r}}=\eta /\left(\left(\Delta \mathrm{T} / \mathrm{T}_{\mathrm{h}}\right)\right)$

where $A$ is the cross-sectional area of the electrode, $K$ represents the thermal conductivity of the redox couple, $\Delta T$ and $d$ are the temperature difference and the distance between two test electrodes, respectively, $\eta$ is the power conversion efficiency and $T_{h}$ is the temperature of the hot side. Open circuit potentials $\left(V_{o c}\right)$ and shorting circuit currents $\left(I_{s c}\right)$ could be obtained from Figure 3e, while power density vs current density curves in diverse temperature differences were shown in Figure 3f. The influence of the different mass ratio of graphene/carbon hollow spheres ( $\mathrm{m}_{\mathrm{GO}}: \mathrm{m}_{\mathrm{PHS}}$ ) on the thermoelectric property of the corresponding thermocell was also tested and illustrated in Figure S13 and Table S1. It is clear that the content of carbon hollow spheres and their distribution significantly affected the output of the thermocell with the highest performance at $\mathrm{m}_{\mathrm{GO}}: \mathrm{m}_{\mathrm{PHS}}=1: 2$. Table S2 compares the best performance of the GHCSA 9-2 aerogel based thermocell with other nanomaterials and nanocomposites based reported in the literature.

Previous studies based on metal electrodes [51-54] have revealed that power conversion efficiencies were less than $0.6 \%$ relative to that of a Carnot engine, which are far from commercial application. The $\mathrm{P}_{\max }$ of the GHCS-aerogel electrodes reached $42 \mu \mathrm{W}$. The maximum output power normalizes to electrode mass up to $6.4 \mathrm{~W} \cdot \mathrm{Kg}^{-1}$, which is much higher than that of reduced graphene 
oxide electrode $\left(3.87 \mathrm{~W} \cdot \mathrm{Kg}^{-1}\right)$ and single wall carbon nanotube electrode $\left(5.2 \mathrm{~W} \cdot \mathrm{Kg}^{-1}\right)$ [52]. The maximum output power normalizes to electrode area up to $1.05 \mathrm{~W} \cdot \mathrm{m}^{-2}$ that is nearly double that of the reduced graphene oxide/single walled carbon nanotube composite electrodes [43] $(0.46$ $\mathrm{W} \cdot \mathrm{m}^{-2}$ ). The energy conversion efficiency of our thermocell relative to Carnot engine reach to $1.4 \%$, which is one order of magnitude higher than that of platinum electrode [55] (0.44\%). This also breaks the previous prediction that it's hard to achieve a power conversion efficiency of $1.2 \%$ of the Carnot efficiency for thermocell [56]. The $P_{\max }$ and $\eta_{r}$ values of the GHCS- aerogel electrodes are more than $100 \%$ higher than those of the carbon nanotube composite electrodes [57,58], as shown in Table S2. The excellent cell performance is contributed by large ESA (shown above) and low circuit resistance (see Figure S14) of the GHCS-aerogel electrodes.

\section{Conclusion}

In summary, submicron sized hollow carbon spheres have been successfully assembled into bulk aerogels, for the first time, in the presence of 2D graphene sheets as crosslinkers. By taking advantages of low apparent density of the hollow sphere, fast electron/ion transfer and large surface area of both porous hollow spheres and graphene sheets, the unique bead-to-sheet polylithic aerogels have showed superior structure and properties with the large specific surface area up to $609 \mathrm{~m}^{2} \cdot \mathrm{g}^{-1}$, high conductivity up to $695 \mathrm{~S} \cdot \mathrm{m}^{-1}$, and ultra-low density down to $51 \mathrm{mg} \cdot \mathrm{cm}^{-}$

3 . Further case study has demonstrated that the GHCS-aerogels electrode based thermocell have possessed maximum output power of $1.05 \mathrm{~W} \cdot \mathrm{m}^{-2}$ and energy conversion efficiency of $1.4 \%$ relative to Carnot engine, so far the best performance among known U-shaped thermocells. The synthetic strategy reported herein is transferable to fabricate a series of novel polylithic aerogels with submicron sized building blocks. The performance of the GHCS-aerogel based thermocell can be further enhanced by embedding Pt nanoparticles in the active electrode [47] or by stacking 
electrode configuration [43], promising for many advanced technological fields such as energy, catalysis, sensor, etc. 


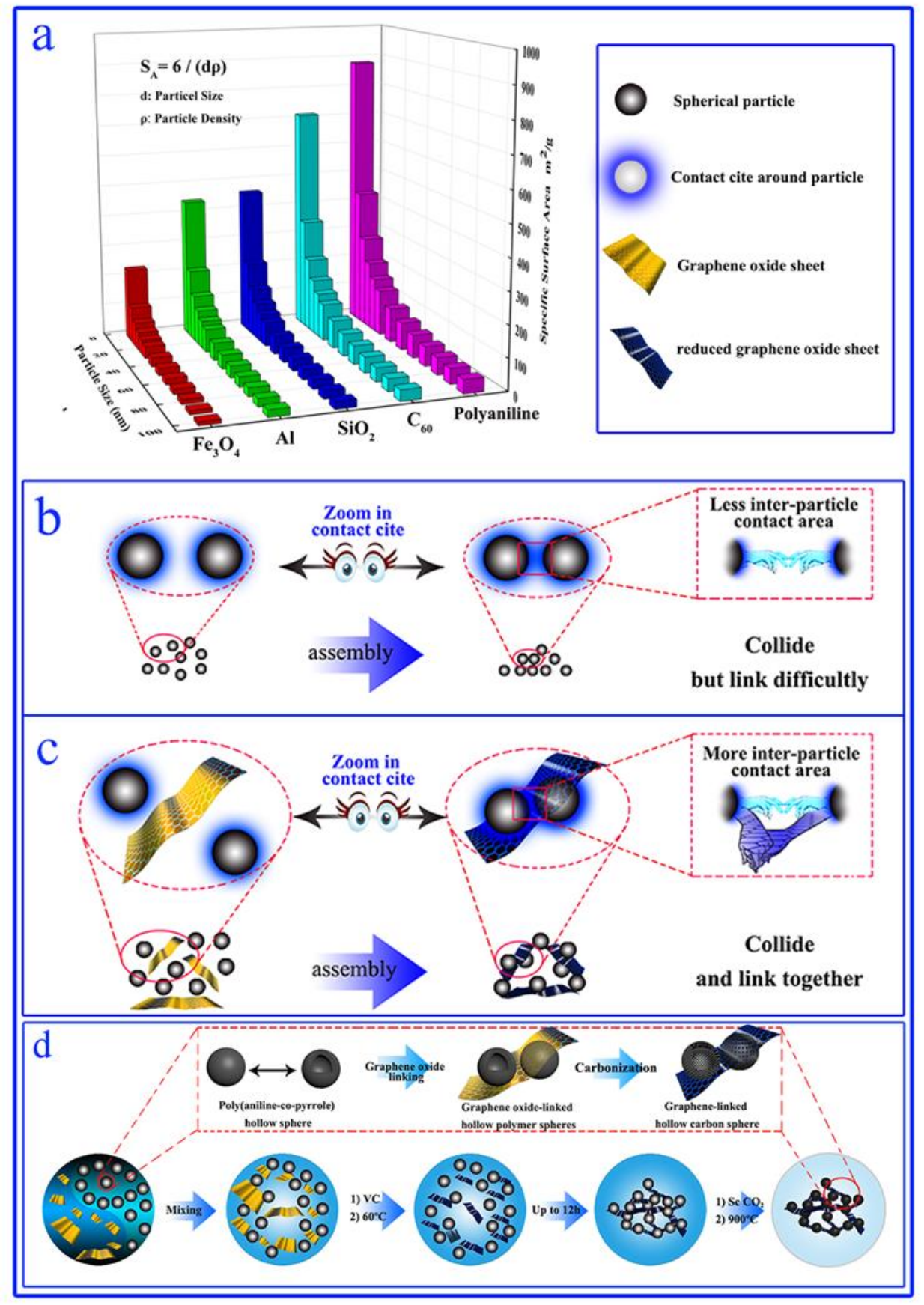

Figure 1. (a) Particle size vs specific surface area curves of different materials, schematic diagram on stacking spherical particles in the absence (b) and presence (c) of 2D sheets, and (d) synthetic route of graphene-crosslinked hollow carbon sphere polylithic aerogel. 

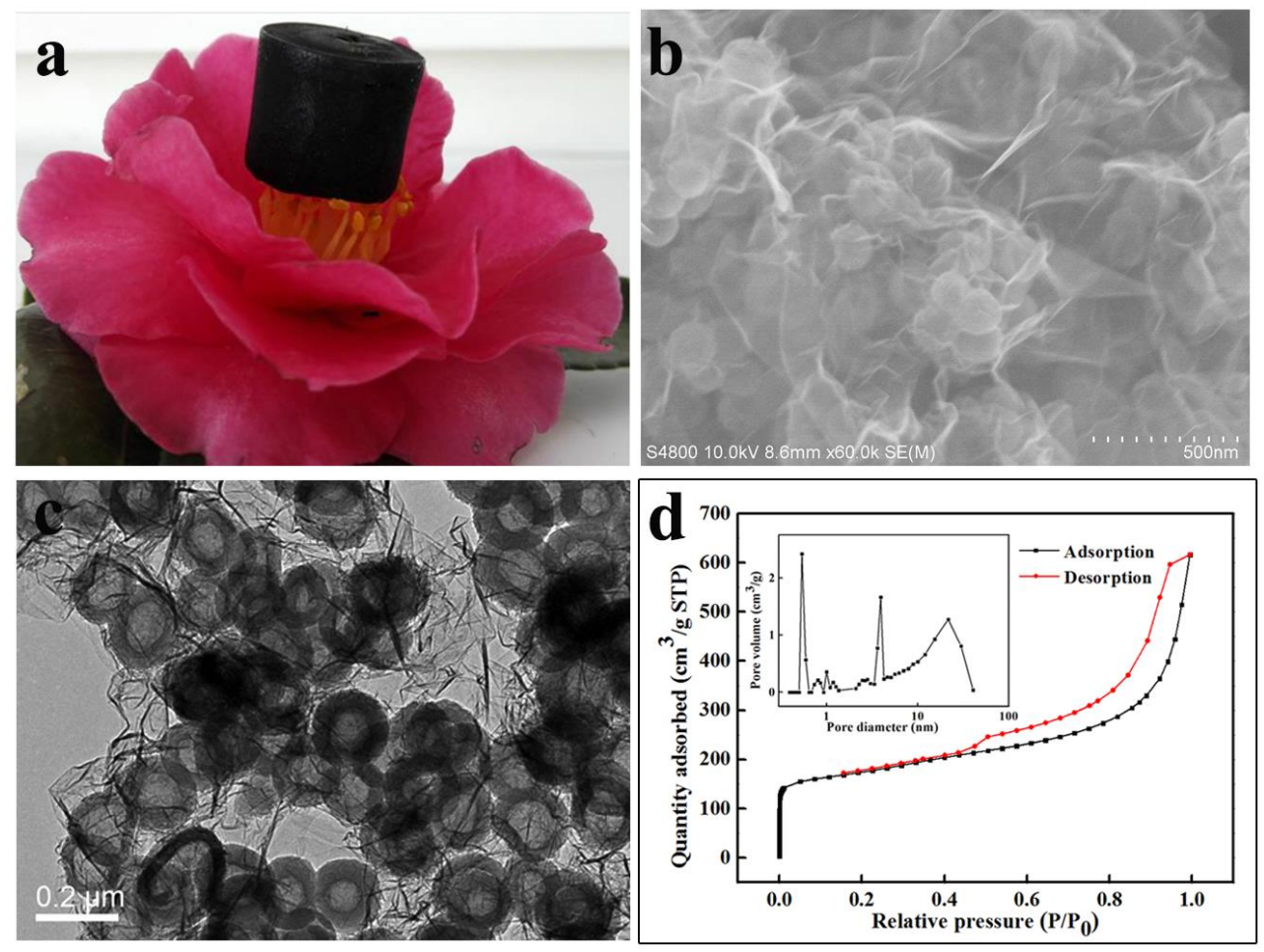

Figure 2. (a) Photo of resulting aerogel monolith on a flower bud, (b) SEM image, (c) TEM image, and (d) $\mathrm{N}_{2}$ sorption isotherm curves of the resulting graphene linked hollow carbon sphere aerogel. Inset in $\mathrm{d}$ is the pore-size distribution curve of the obtained aerogel. 

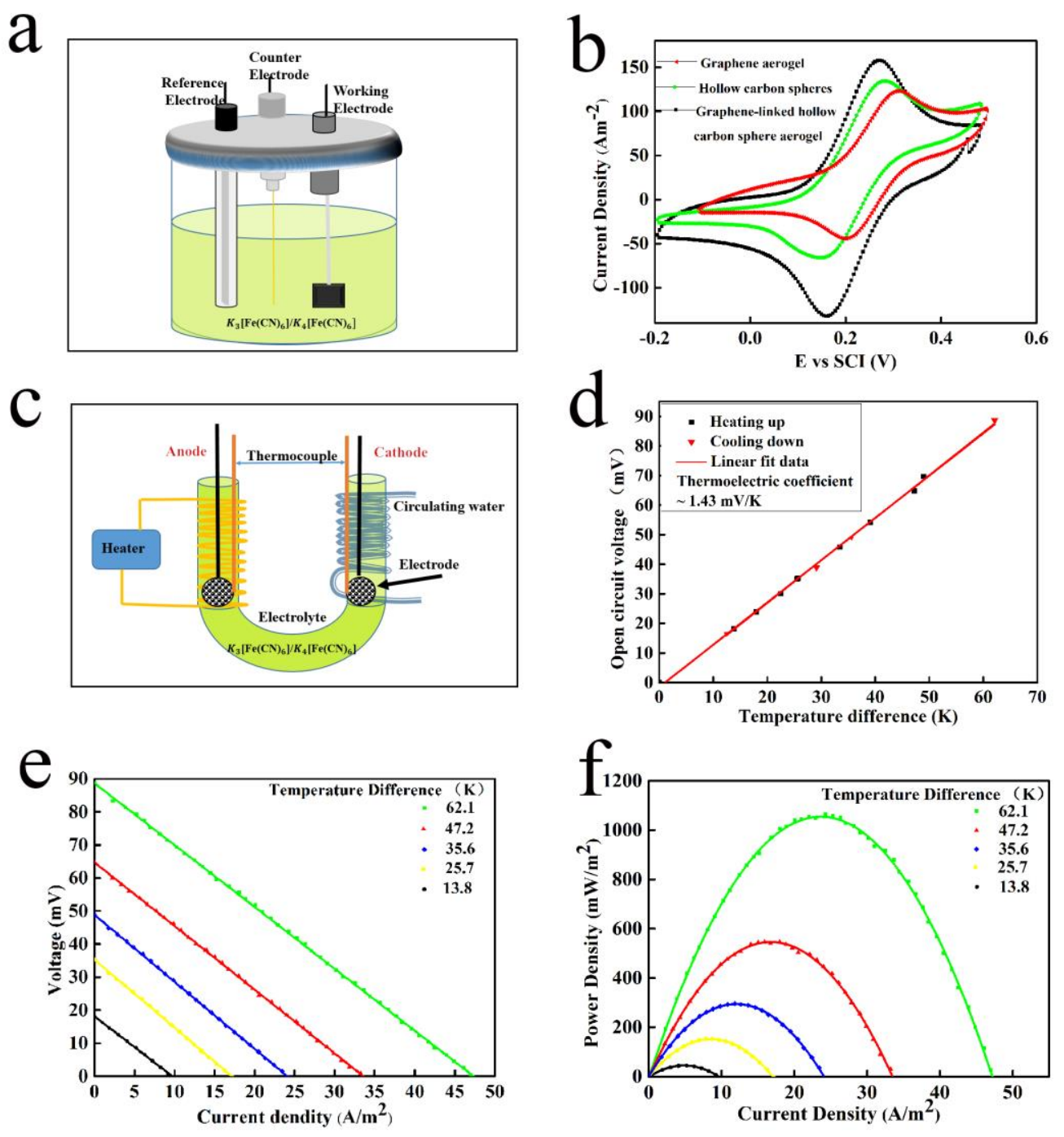

Figure 3. (a) Three-electrode configuration device for recording cyclic voltammogram (CV) curves, (b) recorded CV curves of different working electrodes, (c) schematic diagram of the Ushape thermo-electrochemical cell, (d) dependence of open-circuit potential on the temperature difference between the hot and cold electrodes, (e) cell voltage vs current density curves and (f) power density vs current density curves of the graphene-linked hollow carbon sphere aerogel electrodes with various temperature difference between the hot and cold electrodes. 


\section{Captions:}

Figure 1. (a) Particle size vs specific surface area curves of different materials, schematic diagram on stacking spherical particles in the absence (b) and presence (c) of 2D sheets, and (d) synthetic route of graphene-crosslinked hollow carbon sphere polylithic aerogel.

Figure 2. (a) Photo of resulting aerogel monolith on a flower bud, (b) SEM image, (c) TEM image, and (d) $\mathrm{N}_{2}$ sorption isotherm curves of the resulting graphene linked hollow carbon sphere aerogel. Inset in $\mathrm{d}$ is the pore-size distribution curve of the obtained aerogel.

Figure 3. (a) Three-electrode configuration device for recording cyclic voltammogram (CV) curves, (b) recorded CV curves of different working electrodes, (c) schematic diagram of the Ushape thermo-electrochemical cell, (d) dependence of open-circuit potential on the temperature difference between the hot and cold electrodes, (e) cell voltage vs current density curves and (f) power density vs current density curves of the graphene-linked hollow carbon sphere aerogel electrodes with various temperature difference between the hot and cold electrodes. 
Table 1. The synthetic formulas of graphene-linked hollow carbon sphere aerogel

Note: Theoretical Density $\rho=\left(\mathrm{m}_{\mathrm{PHS}}+\mathrm{m}_{\mathrm{GO}}\right) / \mathrm{V}, \mathrm{V}=10 \mathrm{~mL}$

\begin{tabular}{ccccccc}
\hline Sample ID & $\begin{array}{c}\text { Theoretical } \\
\text { Density } \\
\left(\mathrm{mg} / \mathrm{cm}^{3}\right)\end{array}$ & $\begin{array}{c}\text { Apparent Density } \\
\left(\mathrm{mg} / \mathrm{cm}^{3}\right)\end{array}$ & $\begin{array}{c}\text { Mass ratio } \\
\left(\mathrm{m}_{\mathrm{GO}}:\right. \\
\left.\mathrm{m}_{\mathrm{PHS}}\right)\end{array}$ & $\begin{array}{c}\text { GO } \\
(\mathrm{mg})\end{array}$ & $\begin{array}{c}\text { PHS } \\
(\mathrm{mg})\end{array}$ & $\begin{array}{c}\text { VC } \\
(\mathrm{mg})\end{array}$ \\
\hline GHCSA 4.5-2 & 4.5 & 51 & $1: 2$ & 15 & 30 & 75 \\
GHCSA 9-0.5 & 9 & 65 & $1: 0.5$ & 60 & 30 & 300 \\
GHCSA 9-1 & 9 & 67 & $1: 1$ & 45 & 45 & 225 \\
GHCSA 9-2 & 9 & 67 & $1: 2$ & 30 & 60 & 150 \\
GHCSA 9-5 & 9 & 63 & $1: 5$ & 15 & 75 & 75 \\
GHCSA 16.5-2 & 16.5 & 66 & $1: 2$ & 55 & 110 & 275 \\
\hline
\end{tabular}

Table 2. $\mathrm{N}_{2}$ adsorption data of graphene-linked hollow carbon sphere aerogels

\begin{tabular}{|c|c|c|c|c|}
\hline \multirow[b]{2}{*}{ Sample ID } & \multicolumn{3}{|c|}{$\overline{\operatorname{BET}\left(\mathrm{m}^{2} \cdot \mathrm{g}^{-1}\right)}$} & \multirow{2}{*}{$\begin{array}{l}\text { Pore volume } \\
\left(\mathrm{cm}^{3} \cdot \mathrm{g}^{-1}\right)\end{array}$} \\
\hline & $\begin{array}{c}\text { t-Plot } \\
\text { micropore area }\end{array}$ & $\begin{array}{l}\text { t-Plot external } \\
\text { surface area }\end{array}$ & $\begin{array}{c}\text { BET } \\
\text { surface area }\end{array}$ & \\
\hline GHCSA 9-1 & 171.4 & 437.9 & 609.3 & 1.41 \\
\hline GHCSA 9-2 & 268.1 & 304.5 & 577.6 & 0.82 \\
\hline GHCSA 9-5 & 357.6 & 211 & 569.5 & 0.88 \\
\hline
\end{tabular}

Table 3. Mechanical properties of the graphene-linked hollow carbon sphere aerogels before and after carbonization

\begin{tabular}{lcc}
\hline Sample ID & Young's modulus (MPa) & Yield strength (MPa) \\
NGHCSA 9-1 & 0.385 & 0.145 \\
NGHCSA 9-2 & 0.357 & 0.090 \\
NGHCSA 9-5 & 0.077 & 0.015 \\
GHCSA 9-1 & 0.779 & 0.262 \\
GHCSA 9-2 & 1.825 & 0.403 \\
GHCSA 9-5 & 0.740 & 0.175 \\
\hline
\end{tabular}




\section{Acknowledgements}

This work was financially supported by the National Natural Science Foundation of China (51572285, 21373024) and the National Key Research and Development Program of China (2016YFA0203301). Wenhui Song would like to thank for the finance supports by the UK

Engineering and Physical Sciences Research Council (EPSRC EP/L020904/1 and EP/M026884/1).

\section{References}

[1] A. I. Hochbaum, R. K. Chen, R. D. Delgado, W. J. Liang, E. C. Garnett, M. Najarian, A.Majumdar, P. D. Yang, Nature 451 (2008) 163-167.

[2] Z. H. Dong, H. Ren, C. M. Hessel, J. Y. Wang, R. B. Yu, Q. Jin, etc. Adv. Mater. 26 (2014) 905-909.

[3] C. Wild, M. Huettel, A. Klueter, S. G. Kremb, M. Y. M. Rasheed, B. B. Jorgensen, Nature 428 (2004) 66-70.

[4] H. J. Tang, C. M. Hessel, J. Y. Wang, N. L. Yang, R. Y. Yu, H. J. Zhao, etc. Chem. Soc. Rev. 43 (2014) 4281-4299.

[5] L. M. Wang, Q. Yao, W Shi, S. Y. Qu, L. D. Chen, Mater. Chem. Front. 1 (2017) 741-748.

[6] L. R. Liang, G. M. Chen, C. Y. Guo, Mater. Chem. Front. 1 (2017) 380-386.

[7] X. Y. Lai, J. E. Halpert, D. Wang, Energy Environ. Sci. 5 (2012) 5604-5618.

[8] J. Y. Wang, H. J. Tang, L. J. Zhang, H. Ren, R. B. Yu, Q. Jin, etc. Nature Energy, 1 (2016) 16050.

[9] F. Wang, J. Y. Wang, H. Ren, H. J. Tang, R. B. Yu, D. Wang, Inorg. Chem. Front. 3 (2016) 365-369. 
[10] H. Ren, J. J. Sun, R. B. Yu, M. Yang, L. Gu, P. R. Liu, etc. Chem. Sci. 7 (2016) 793-798.

[11] J. Y. Wang, H. J. Tang, H. Wang, R. B. Yu, D. Wang, Mater. Chem. Front. 1 (2017) 414430.

[12] J. Y. Wang, H. J. Tang, H. Ren, R. B. Yu, J. Qi, D. Mao, etc. Adv. Sci. 1 (2014) 1400011

[13] S. S. Kistler, Nature 127 (1931) 741.

[14] N. Husing, U. Schubert, Angew. Chem. Int. Ed. 37 (1998), 23-45.

[15] A. S. Dorcheh, M. H. Abbasi, J. Mater. Process. Technol. 199 (2008) 10-26.

[16] S. A. Al-Muhtaseb, J. A. Ritter, Adv. Mater. 15 (2003) 101-114.

[17] D. Guo, P. Cai, J. Sun, W. He, X. Wu, T. Zhang, X. Wang, X. Zhang, Carbon 99 (2016) 571578.

[18] L. Chen, B. Wei, X. Zhang, Chun Li, Small 9 (2013) 2331-2340

[19] S. M. Jung, D. J. Preston, H. Y. Jung, Z. T. Deng, E. N. Wang, J. Kong, Adv. Mater. 28 (2016) 1413-1419.

[20] V. Sayevich, B. Cai, A. Benad, D. Haubold, L. Sonntag, N. Gaponik, etc. Angew. Chem. Int. Ed. 55 (2016) 6334-6338.

[21] A. E. Aliev, J. Y. Oh, M. E. Kozlov, A. A. Kuznetsov, S. L. Fang, A. F. Fonseca, etc. Science 323 (2009) 1575-1578.

[22] R. Menzel, S. Barg, M. Miranda, D. B. Anthony, S. M. Bawaked, M. Mokhtar, etc. Adv. Funct. Mater. 25 (2015) 28-35.

[23] B. Cai, D. Wen, W. Liu, A. K. Herrmann, A. Benad, A. Eychmuller, Angew. Chem. Int. Ed. 54 (2015) 13101-13105.

[24] C. Zhu, T. Y. Liu, F. Qian, T. Y. J. Han, E. B. Duoss, J. D. Kuntz, C. M. Spadaccini, M. A. Worsley, Y. Li, Nano Lett. 16 (2016) 3448-3456. 
[25] J. L. Mohanan, I. U. Arachchige, S. L. Brock, Science 307 (2005) 397-400.

[26] J. Qi, X. Y. Lai, J. Y. Wang, H. J. Tang, H. Ren, Y. Yang, etc. Chem. Soc. Rev. 44 (2015) 6749-6773.

[27] S. H. Sun, C. B. Murray, D. Weller, L. Folks, A. Moser, Science 287 (2000) 1989-1992.

[28] J. Wijnhoven, W. L. Vos, Science 281 (1998) 802-804.

[29] G. Oberdorster, E. Oberdorster, J. Oberdorster, Environ. Health Perspect. 113 (2005) 823839.

[30] F. Xu, Z. Tang, S. Huang, L. Chen, Y. Liang, W. Mai, H. Zhong, R. Fu, D. Wu, Nat. Commun. $6(2015) 7221$.

[31] X. Huang, X. Qi, F. Boey, H. Zhang, Chem. Soc. Rev. 41 (2012) 666-686.

[32] C. Zhu, T. Y. J. Han, E. B. Duoss, A. M. Golobic, J. D. Kuntz, C. M. Spadaccini, etc. Nat. Commun. 6 (2015) 8.

[33] Z. Q. Lin, Z. P. Zeng, X. C. Gui, Z. K. Tang, M. C. Zou, A. Y. Cao, Adv. Energy Mater. 6 (2016) 26.

[34] H. Tang, P. B. Gao, Z. H. Bao, B. Zhou, J. Shen, Y. F. Mei, G. M. Wu, Nano Res. 8 (2015) $1710-1717$.

[35] S. Nardecchia, D. Carriazo, M. L. Ferrer, M. C. Gutierrez, F. del Monte, Chem. Soc. Rev. 42 (2013) 794-830.

[36] R. Sun, H. Y. Chen, Q. W. Li, Q. J. Song, X. T. Zhang, Nanoscale 6 (2014) 12912-12920.

[37] K. S. W. Sing, D. H. Everett, R. A. W. Haul, L. Moscou, R. A. Pierotti, J. Rouquerol, T. Siemieniewska, Pure Appl. Chem. 57 (1985) 603-619.

[38] Y. Zhu, S. Murali, W. Cai, X. Li, J. W. Suk, J. R. Potts, R. S. Ruoff, Adv. Mater. 22 (2010) 3906-3924. 
[39] M. Litschauer, M. A. Neouze, E. Haimer, U. Henniges, A. Potthast, T. Rosenau, F. Liebner, Cellulose 18 (2011) 143-149.

[40] A. Harley-Trochimczyk, T. Pham, J. Chang, E. Chen, M. A. Worsley, A. Zettl, W. Mickelson, R. Maboudian, Adv. Funct. Mater. 26 (2016) 433-439.

[41] Y. Mua, T. I. Quickenden, J. Electrochem. Soc. 143 (1996) 2558-2564.

[42] R. Hu, B. A. Cola, N. Haram, J. N. Barisci, S. Lee, S. Stoughton, G. Wallace, C. Too, M. Thomas, A. Gestos, M. E. d. Cruz, J. P. Ferraris, A. A. Zakhidov, R. H. Baughman, Nano Lett. 10 (2010) 838-846;

[43] M. S. Romano, N. Li, D. Antiohos, J. M. Razal, A. Nattestad, S. Beirne, S. L. Fang, Y. S. Chen, R. Jalili, G. G. Wallace, R. Baughman, J. Chen, Adv. Mater. 25 (2013) 6602-6606.

[44] L. Chen, X. J. Wang, X. T. Zhang, H. M. Zhang, J. Mater. Chem. 22 (2012) 22090-22096.

[45] Y. B. Li, H. M. Zhang, Y. Wang, P. R. Liu, H. Y. Yang, X. D. Yao, etc. Energy Environ. Sci. $7(2014) 3720-3726$.

[46] M. Pacios, M. del Valle, J. Bartroli, M. J. Esplandiu, J. Electroanal. Chem. 619 (2008) 117124.

[47] H. Im, T. Kim, H. Song, J. Choi, J. S. Park, R. Ovalle-Robles, H. D. Yang, K. D. Kihm, R. H. Baughman, H. H. Lee, T. J. Kang, Y. H. Kim, Nat. Commun. 7 (2016) 10600.

[48] R. S. Nicholson, Anal. Chem. 37 (1965) 1351-1355.

[49] P. F. Salazar, S. Kumar, B. A. Cola, J. Electrochem. Soc. 159 (2012) B483-B488.

[50] A. Zahoor, M. Christy, Y. J. Hwang, Y. R. Lim, P. Kim, K. S. Nahm, Appl. Catal. B-Environ. 147 (2014) 633-641.

[51] S. M. Lyth, Y. Nabae, S. Moriya, S. Kuroki, M. Kakimoto, J. Ozaki, S. Miyata, J. Phys. Chem. C. 113 (2009) 20148-20151. 
[52] T. J. Kang, S. Fang, M. E. Kozlov, C. S. Haines, N. Li, Y. H. Kim, Y. Chen, R. H. Baughman, Adv. Funct. Mater. 22 (2012) 477-489.

[53] M. S. Romano, S. Gambhir, J. M. Razal, A. Gestos, G. G. Wallace, J. Chen, J. Therm. Anal. Calorim. 109 (2012) 1229-1235.

[54] A. Gunawan, C. H. Lin, D. A. Buttry, V. Mujica, R. A. Taylor, R. S. Prasher, P. E. Phelan, Nanoscale Microscale Thermophys. Eng. 17 (2013) 304-323.

[55] T. I. Quickenden, C. F. Vernon, Sol. Energy 36 (1986) 63-72.

[56] T. I. Quickenden, Y. Mua, J. Electrochem. Soc. 142 (1995) 3985-3994.

[57] W. J. Qian, M. J. Li, L. H. Chen, J. H. Zhang, C. K. Dong, RSC. Adv. 5 (2015) 97982-97987.

[58] W. J. Qian, M. X. Cao, F. Xie, C. K. Dong, Nano-Micro Lett. 8 (2016) 240-246. 


\section{Supplementary materials}

\section{Assembling Hollow Carbon Sphere-Graphene Polylithic Aerogels for Thermoelectric Cells}

Dapeng Dong, Haitao Guo, Guangyong Li, Lifeng Yan, Xuetong Zhang* and Wenhui Song*

\section{Materials}

Graphene oxide (GO) was prepared from graphite powder by a modified Hummers method reported in our previous study [1-3]. The GO was dispersed in deionized water to obtain $8 \mathrm{mg} \cdot \mathrm{mL}^{-}$ ${ }^{1}$ suspension. Poly(aniline-co-pyrrole) hollow spheres (PHS) were synthesized according to the procedure reported elsewhere[4]. Typically, $0.38 \mathrm{~mL}$ aniline, $0.29 \mathrm{~mL}$ pyrrole and $0.06 \mathrm{~g}$ TX-100 were dispersed in $57 \mathrm{~mL}$ deionized water with magnetic stirring for $30 \mathrm{~min}$ and ultrasonicated for another $30 \mathrm{~min}$ to obtain a uniform solution. After that, the solution was maintained at $3 \sim 5^{\circ} \mathrm{C}$ for $1 \mathrm{~h}$ before oxidative polymerization. Then $3 \mathrm{~mL} 2.8 \mathrm{M}$ aqueous solution of APS cooled at $3 \sim 5{ }^{\circ} \mathrm{C}$ for $1 \mathrm{~h}$ was added to the above mixture in one portion. The resulting solution was stirred for another $0.5 \mathrm{~min}$ to ensure complete mixing and then reaction was allowed to proceed without stirring for 24 hours at $3 \sim 5{ }^{\circ} \mathrm{C}$. Finally, the product was washed with deionized water until filtrate became colorless and final suspension was concentrated to $45 \mathrm{mg} \cdot \mathrm{mL}^{-1}$. The yield of PHS is $76.8 \%$. 


\section{Figures}

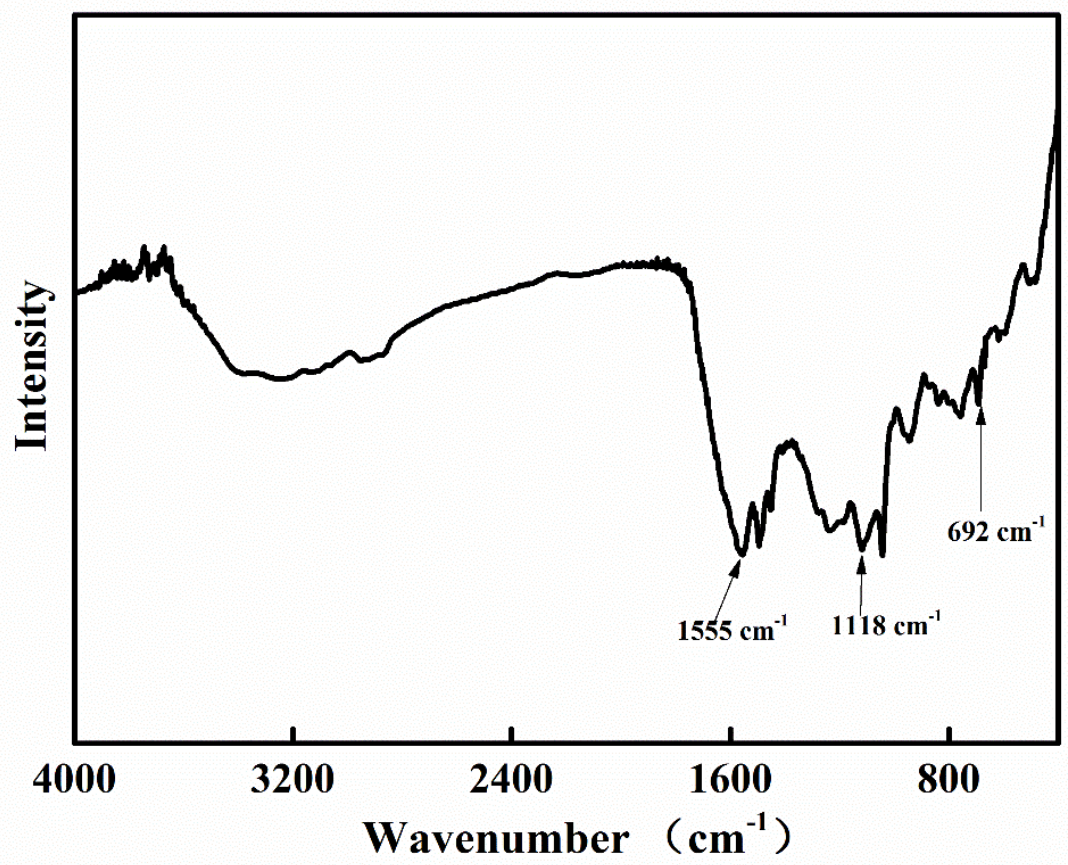

Figure S1. FTIR spectrum of poly(aniline-co-pyrrole) hollow spheres.

The chemical structure of the poly(aniline-co-pyrrole) hollow spheres was confirmed by FTIR spectrum in Figure S1. The peak at $1555 \mathrm{~cm}^{-1}$ should be due to the resonance of quinonoid phenyl ring $\mathrm{C}-\mathrm{C}$ stretching of polyaniline at $1575 \mathrm{~cm}^{-1}$ and the $\mathrm{C}=\mathrm{C} / \mathrm{C}-\mathrm{C}$ stretching mode of polypyrrole at $1564 \mathrm{~cm}^{-1}$, which provides convincing proof to confirm the direct linkage of aniline and pyrrole monomers [5]. The peak at $1118 \mathrm{~cm}^{-1}$ can be attributed to $\mathrm{C}-\mathrm{H}$ in-plane bending on the $1,2,4$ substituted benzene of polyaniline[6]. The peak at $692 \mathrm{~cm}^{-1}$ is attributed to the $\mathrm{C}-\mathrm{H}$ in-plane bending on the 1,3-substituted benzene ring[7], which may be induced by the attacking of active pyrrole units to the meta-position of benzene ring. Therefore, these observed results proved that these hollow spheres were made from the poly(aniline-co-pyrrole) via the oxidation polymerization of a mixture of aniline and pyrrole. 

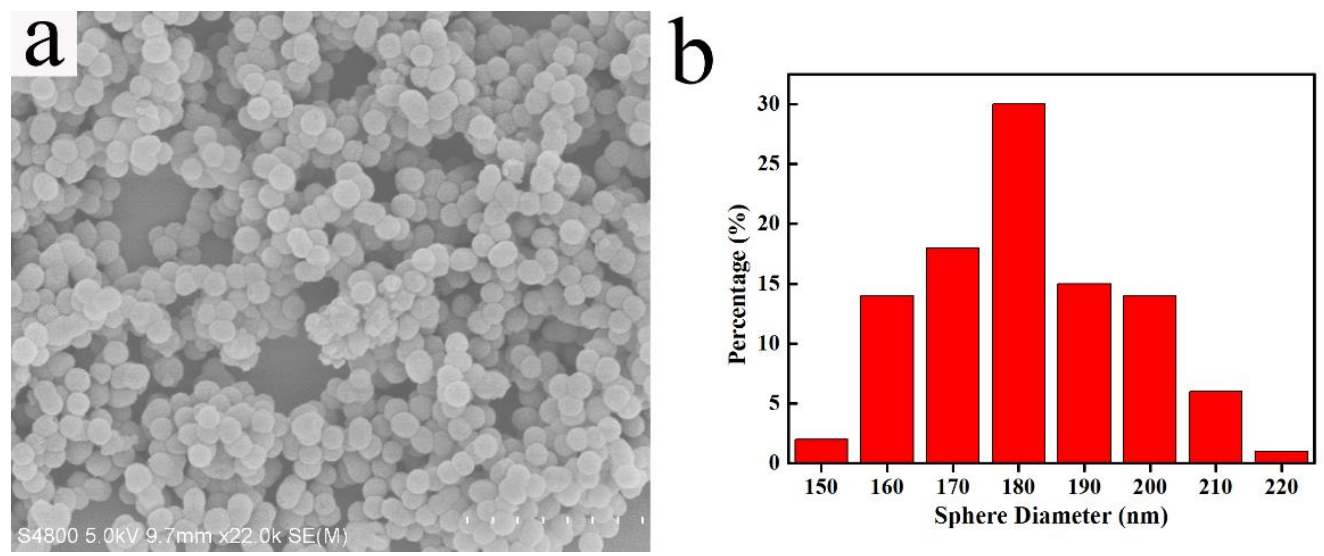

Figure S2. (a) Scanning Electron Microscopy (SEM) image of poly(aniline-co-pyrrole) hollow spheres, and (b) its sphere diameter distribution histogram. 


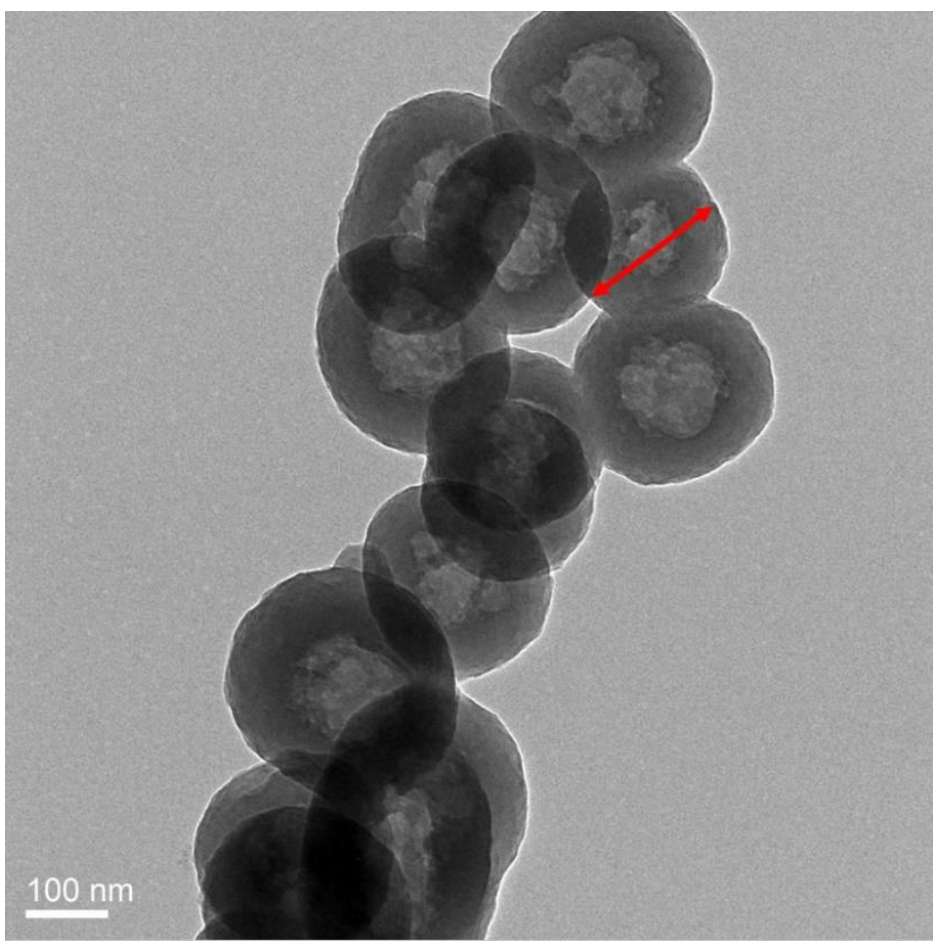

Figure S3. Transmission Electron Microscopy (TEM) image of poly(aniline-co-pyrrole) hollow spheres, the diameter indicated by red arrow is $186 \mathrm{~nm}$. 

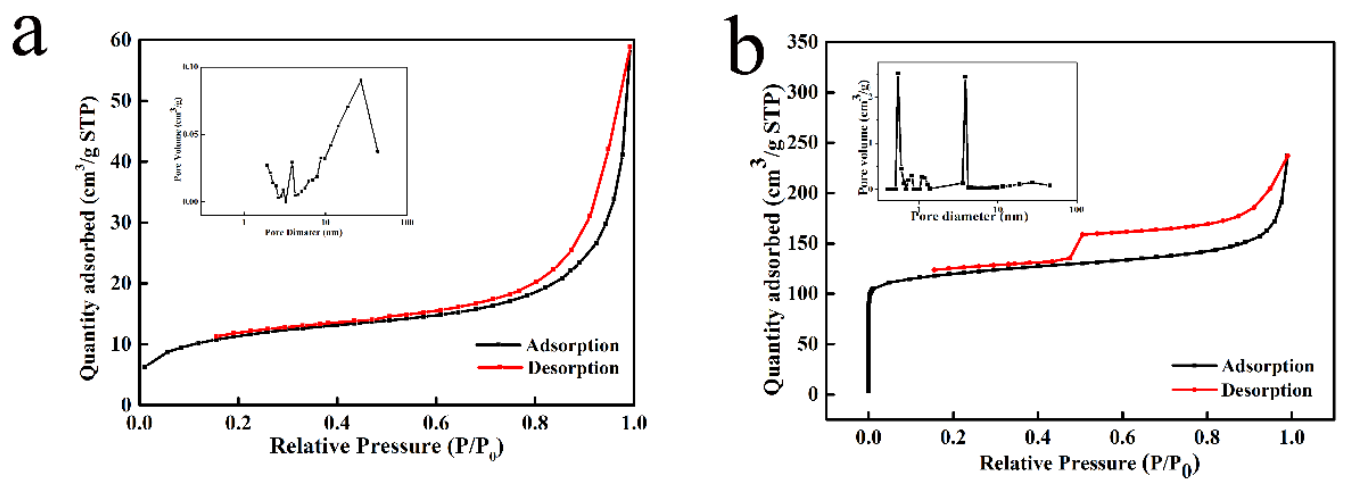

Figure S4. $\mathrm{N}_{2}$ adsorption-desorption isotherms of (a) poly(aniline-co-pyrrole) hollow spheres, and (b) hollow carbon spheres (HCS), insets are the pore-size distributions curves.

The nitrogen adsorption-desorption isotherm of hollow carbon spheres exhibits characteristics of type I/IV according to the classification of the International Union of Pure and Applied Chemistry. A very high nitrogen uptake at low relative pressure demonstrates the existence of tremendous micropore within the shell, whereas the hysteresis loop at high relative pressure indicates the presence of mesopores. The Brunauer-Emmett-Teller (BET) surface area $\left(\mathrm{S}_{\mathrm{BET}}\right)$ is calculated to be as high as $373.7 \mathrm{~m}^{2} \cdot \mathrm{g}^{-1}$. The $\mathrm{S}_{\text {BET }}$ of carbon precursor PHS is only $38.7 \mathrm{~m}^{2} \cdot \mathrm{g}^{-1}$. This distinct difference of the surface area of the hollow spheres indicates that a large number of pores within the shell of hollow carbon spheres were generated during carbonization treatment. This is because the resulting carbon shell are composed of turbostratic carbon sheets and clusters and their disordered packing leads to free volume and porosity $[8,9]$.

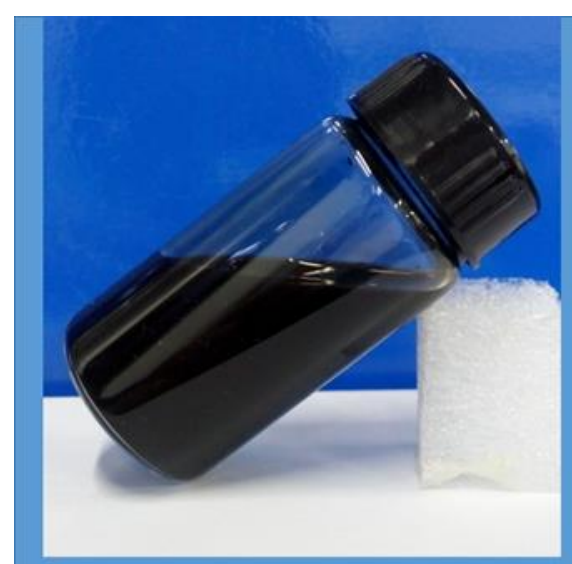

GO+PHS dispersion

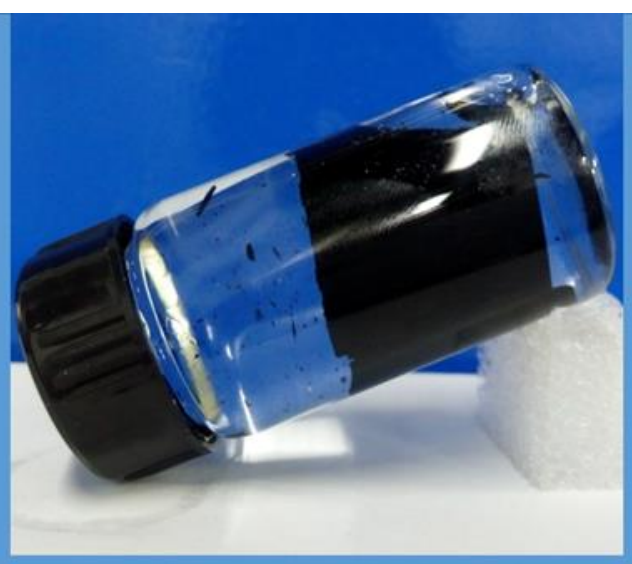

Composite hydrogel

Figure S5. Photo images of the mixed dispersion of graphene oxide (GO) and Poly(aniline-copyrrole) hollow spheres (PHS) before and after addition of Vitamin C (VC). 


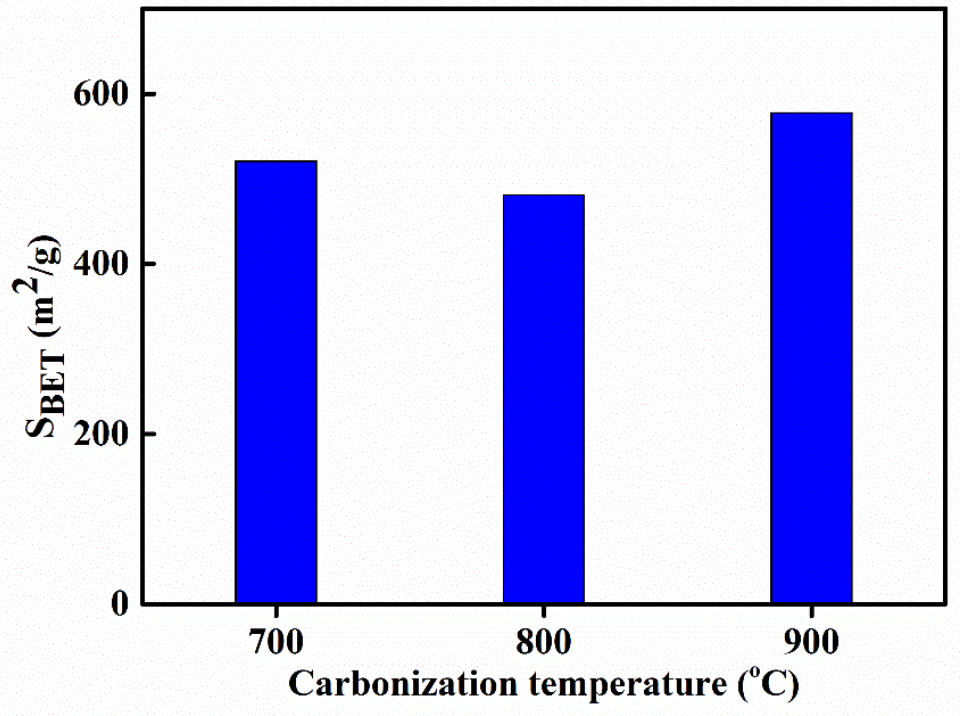

Figure S6. Specific surface area $\left(\mathrm{S}_{\mathrm{BET}}\right)$ of GHCSA 9-2 obtained at various carbonization temperature. 


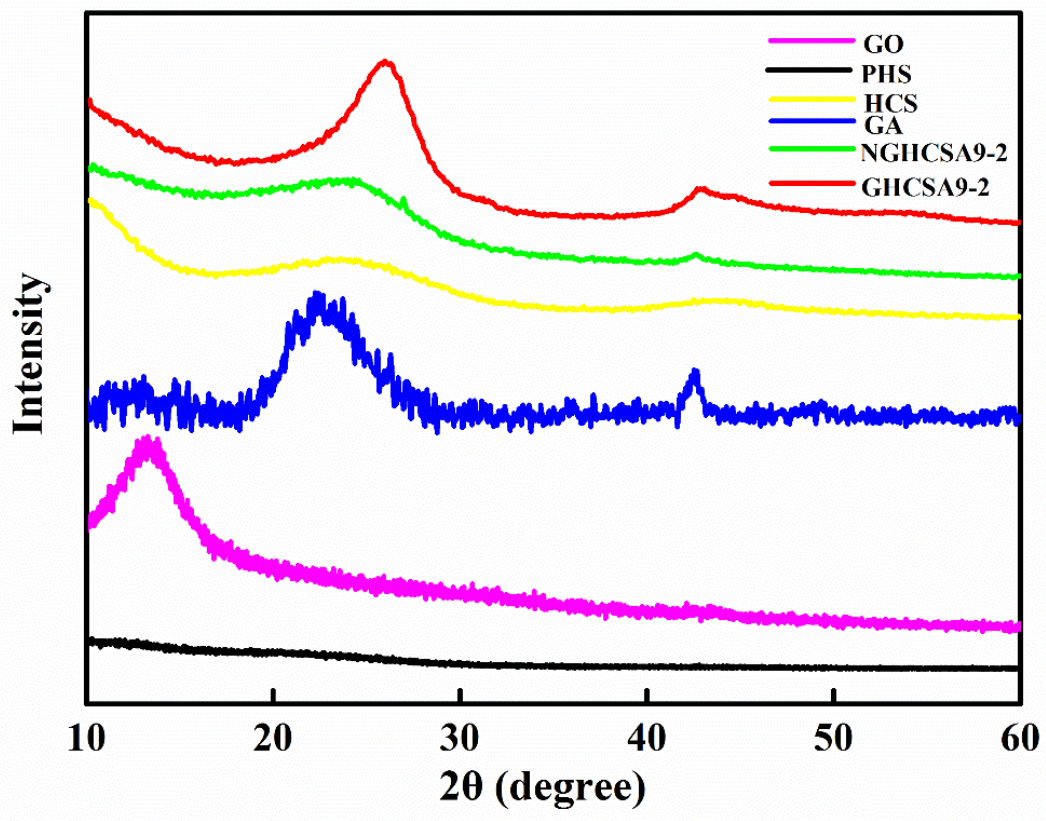

Figure S7. X-ray diffraction (XRD) profiles of graphene oxide (GO), poly(aniline-co-pyrrole) hollow spheres (PHS), hollow carbon spheres (HCS), graphene aerogel after carbonization (GA), graphene-linked hollow carbon sphere aerogels before (NGHCSA 9-2) and after carbonization (GHCSA 9-2).

The XRD patterns reveal a crystal form of graphene-linked hollow carbon sphere aerogel as shown in Figure S7. The diffraction peak of GO centred at $13.2^{\circ}$ corresponds to the interlayer spacing of $0.7 \mathrm{~nm}$. The interlayer spacing of GO is much larger than that of pristine graphite $(\sim 0.34 \mathrm{~nm})$ owing to the fact that many oxygen-containing groups, such as hydroxyl, epoxy and carboxyl, were introduced onto graphene layers during the oxidation process [10,11]. As for GA, a broad diffraction peak occurs at $2 \theta=22.3^{\circ}$ corresponding to the (002) plane of graphite structure. The interlayer space of the GA is calculated to be $0.398 \mathrm{~nm}$. The formation of the graphite-like structure of GA indicates the highly efficient removal of oxygen-containing groups during carbonization. As for PHS, no obvious diffraction peaks are observed, indicating that an amorphous structure was formed via the oxidation polymerization of a mixture of aniline and pyrrole[7]. At the same time, 
HCS shows amorphous structures from the broad band. Comparison of the broad XRD peaks of the resulting aerogels before and after carbonization indicates that the frameworks of the aerogels are composed of hollow carbon spheres bonded by graphene sheets, and there is an increase of denser and ordered structure along their stacking direction. Aerogel before carbonization appears as two broad and weak diffusion halo peaks within the range of $2 \theta=20^{\circ} \sim 30^{\circ}$ and $2 \theta=40^{\circ} \sim 50^{\circ}$, indicating poor crystalline structure in aerogel before carbonization. In contrast, the carbonized graphene-linked hollow carbon sphere aerogel has two relative strong diffraction peaks, which are corresponding to the (002) and (100) lattice plane of the multilayered graphene [12]. The result proves that the aerogel became crystallized after carbonization. The interlayer spaces of the aerogels are calculated to be $0.366 \mathrm{~nm}$ before carbonization, and $0.35 \mathrm{~nm}$ after carbonization. These values are much lower than that of graphene oxide precursor $(0.7 \mathrm{~nm})$ while slightly higher than that of natural graphite $(0.337 \mathrm{~nm})$. These results suggest the existence of $\pi-\pi$ interactions between graphene sheets and hollow carbon spheres in the aerogels, contributing the denser stacking between the graphene and hollow spheres during carbonization. 


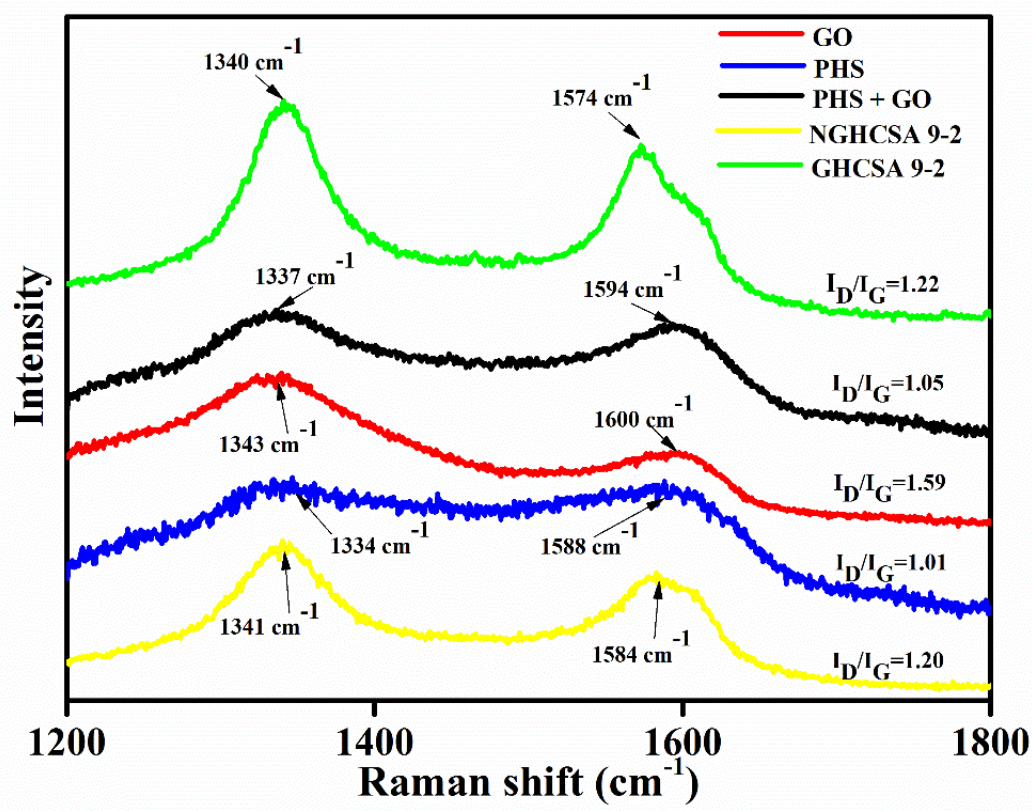

Figure S8. Raman spectra of graphene oxide (GO), poly(aniline-co-pyrrole) hollow spheres (PHS), the mixture of poly(aniline-co-pyrrole) hollow spheres and graphene oxide (PHS + GO), graphene-linked hollow carbon sphere aerogels before (NGHCSA 9-2) and after carbonization (GHCSA 9-2).

To understand the structure and related electronic properties of the samples, Raman spectroscopy analysis was conducted (Figure S8). There are two prominent peaks at $\sim 1340 \mathrm{~cm}^{-1}$ and $\sim 1590 \mathrm{~cm}^{-}$ ${ }^{1}$ corresponding to the D- and G-bands, respectively. It has been reported that the D-band originates from the disorder-induced mode associated with structural defects and imperfections, while the Gband corresponds to the first-order scattering of the $\mathrm{E}_{2 \mathrm{~g}}$ mode from the $\mathrm{sp}^{2}$ carbon domains [13]. The intensity ratio $\mathrm{I}_{\mathrm{D}} / \mathrm{I}_{\mathrm{G}}$ is often used as a measure of the disorder degree in graphitic materials [14]. The Raman spectrum of GO displays two bands located at $1343 \mathrm{~cm}^{-1}$ and $1600 \mathrm{~cm}^{-1}$. The Raman spectrum of PHS displays two bands located at $1334 \mathrm{~cm}^{-1}$ and $1588 \mathrm{~cm}^{-1}$. The mixture of poly(aniline-co-pyrrole) hollow spheres and graphene oxide shows two convergent bands at around $1337 \mathrm{~cm}^{-1}$ and $1594 \mathrm{~cm}^{-1}$. The Raman spectrum of the mixture shows the characteristic bands of GO and an enhanced intensity of the G-band around $1594 \mathrm{~cm}^{-1}$, which indicates strong interactions between PHS and GO sheets [15]. At the same time, compared with the PHS, the mixture exhibits small up-shift in Raman peaks. Those results confirmed that there are strong the 
$\pi-\pi$ interactions between polymeric chains of PHS and the GO sheets [16], resulting in the beadon-sheet stacking in the PHS-GO composites.

The chemical structure of the polylithic aerogel was also confirmed by Raman spectroscopy. As compared to the aerogel before carbonization, the G-bands of the graphene-linked hollow carbon sphere aerogel has a $11 \mathrm{~cm}^{-1}$ blue shift. This result is consistent with the characteristic changes occurring from amorphous carbon (a-C) to nanocrystalline graphite (nc-G) in the amorphization trajectory[17]. Furthermore, [15] the higher value of the $\mathrm{I}_{\mathrm{D}} / \mathrm{I}_{\mathrm{G}}$ band intensity ratio of the polylithic aerogel indicates more defects generated in the presence of numerous micropores of the hollow carbon spheres during carbonization. The results show that the assembly of submicron spheres is due to the interaction between spheres and graphene sheets. In addition, the value of intensity ratio $\mathrm{I}_{\mathrm{D}} / \mathrm{I}_{\mathrm{G}}$ increased with increasing the graphene content. This may be related to the inherent defects of GO during oxidation process. 

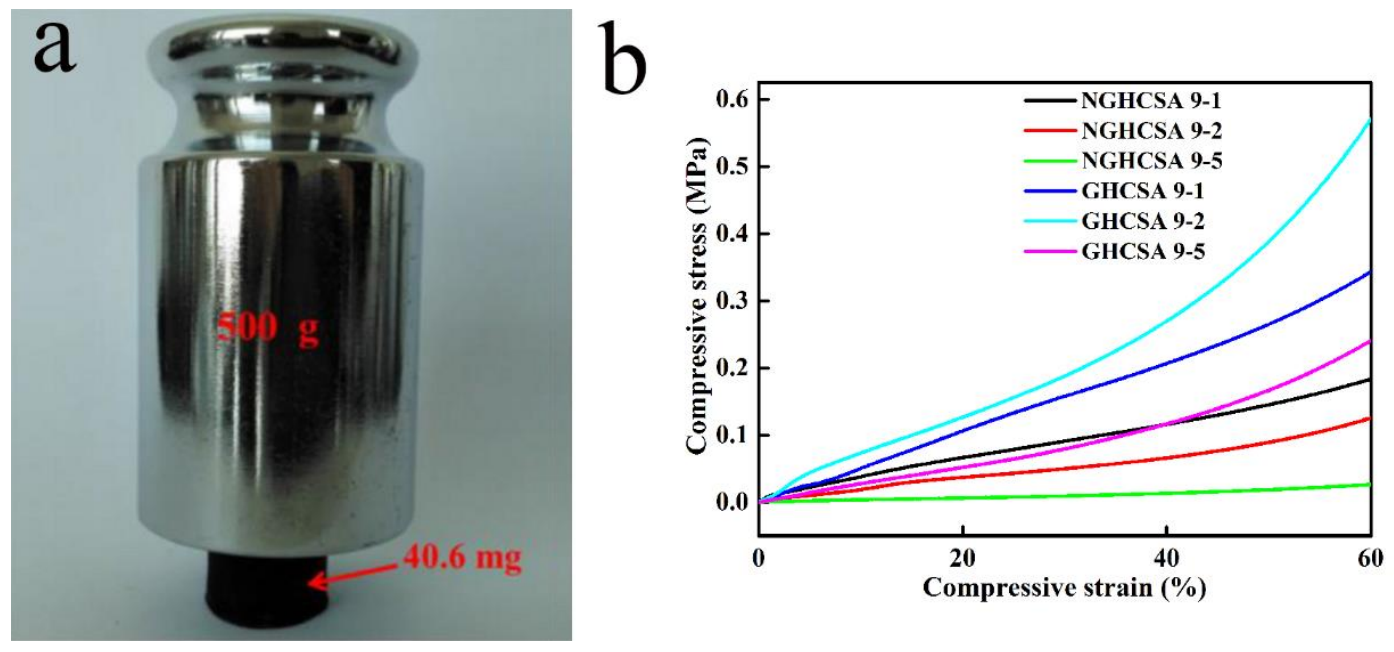

Figure S9. (a) A $40.6 \mathrm{mg}$ graphene-linked hollow carbon aerogel pillar supporting a $500 \mathrm{~g}$ counterpoise, more than 12000 times of its own weight, (b) stress-strain curves of graphenelinked hollow carbon aerogels before and after carbonization

Two stages[18] were observed from the stress-strain curve (Figure S9b) of aerogels, named as elastic deformation and plastic deformation, respectively. Elastic deformation was reversible and linear region, mainly contributed by the solid walls of various pores in aerogels. The plastic deformation was a combination of reversible and non-reversible deformation of the solid walls, the collapse of the porous structure and desicification of the solid walls in the aerogels after the yield point. Table 3 showed mechanical properties of the aerogels before and after carbonization with various mass ratios of HPS:GO. The Young's moduli in the elastic region are in the range of $0.077 \sim 1.825 \mathrm{MPa}$, while those moduli in the plastic region are in the range of 0.015 0.403 MPa. 


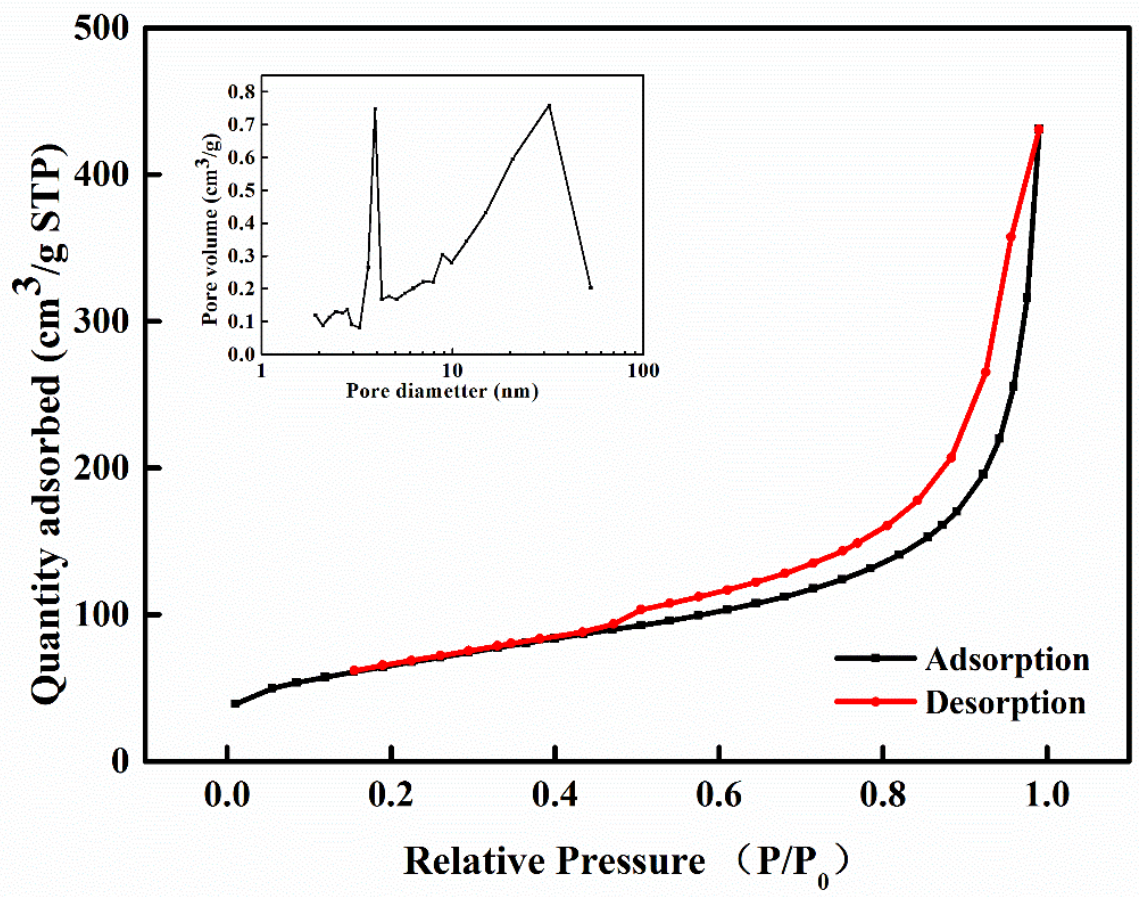

Figure S10. $\mathrm{N}_{2}$ sorption isotherm curves of the resulting graphene linked hollow carbon sphere aerogel before carbonization. Inset is the pore-size distribution curve of the obtained aerogel.

The $\mathrm{N}_{2}$ adsorption isotherm of graphene linked hollow carbon sphere aerogel before carbonization is of type IV attributed to monolayer-multilayer adsorption, suggesting the mesoporous nature of the aerogel[15]. The $\mathrm{N}_{2}$ adsorption-desorption isotherm of the aerogel exhibits a hysteresis loop with the character of $\mathrm{H} 4$, indicating the presence of slit-like pores[19]. The pore-size distribution plots are calculated using the Barrett-Joyner-Halenda (BJH) method from the desorption branch of the isotherm. The pore size is mainly about $4 \mathrm{~nm}$ and $30 \mathrm{~nm}$ on average as shown in Figure S10. The Brunauer-Emmett-Teller (BET) analysis further quantifies the specific surface area of the aerogel with a value of $233.5 \mathrm{~m}^{2} \mathrm{~g}^{-1}$. 


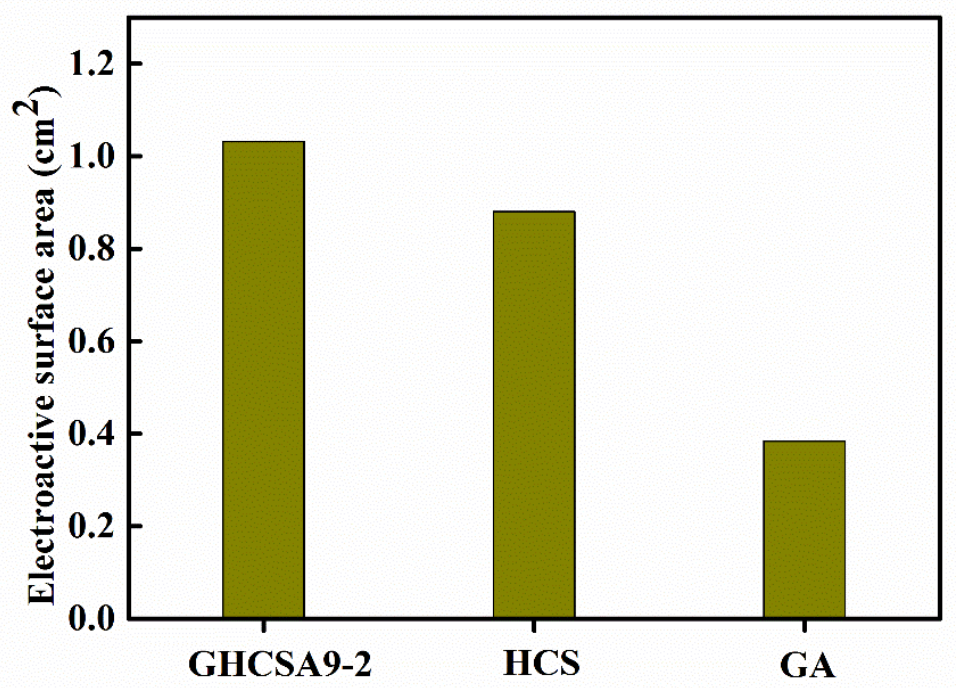

Figure S11. Electroactive surface area of the various electrodes, graphene-linked hollow carbon sphere aerogel (GHCSA9-2), hollow carbon spheres (HCS), graphene aerogel (GA). 

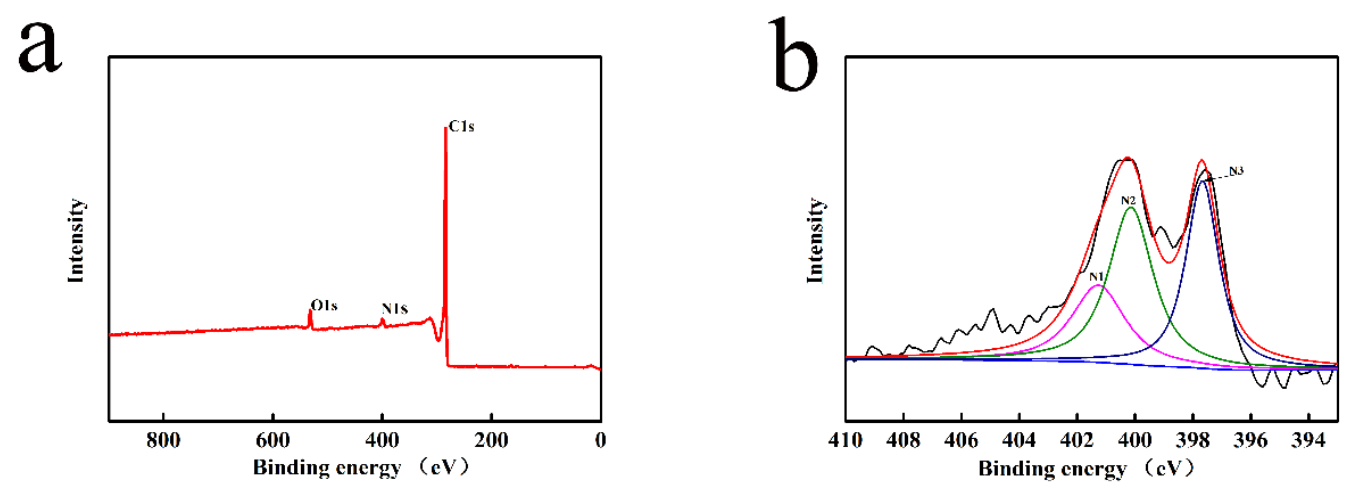

Figure S12. X-ray photoelectron spectroscopy (XPS) spectrum of graphene-linked hollow carbon sphere aerogel: full scan (a) and high resolution N1s spectrum (b). The black and red lines are the raw and fitted spectrum. The dark blue, green, and magenta lines correspond to pyridine-like $\mathrm{N}(398.1 \mathrm{eV})$, pyrrole-like $\mathrm{N}(399.9 \mathrm{eV})$, and quaternary $\mathrm{N}(401.3 \mathrm{eV})$, respectively.

The polylithic aerogel showed oxygen $(531.8 \mathrm{eV})$, nitrogen $(399.5 \mathrm{eV})$ and carbon $(283.7 \mathrm{eV})$ signals in the XPS spectrum. A trace amount of oxygen was mainly residue from the reduced graphene oxide which was used as crosslinker. Nitrogen was derived from the poly(aniline-copyrrole) hollow spheres. XPS characterization indicated that about 3.3\% nitrogen was introduced to the aerogel. Quaternary nitrogen replaces a carbon atom in the graphitic matrix and the removal of one electron decreases the aromaticity of the system[20]. For pyrrole-like N, the uptake of a proton, as in the case of the quaternary nitrogen, needs the donation of an electron from the aromatic system, with subsequent loss of aromaticity[21]. Thus, these two types of nitrogen are favorable for promoting the oxidation of $\left[\mathrm{Fe}(\mathrm{CN})_{6}\right]^{4-}$ to $\left[\mathrm{Fe}(\mathrm{CN})_{6}\right]^{3-}$. pyridine-like $\mathrm{N}$, with a lone electron pair, can behave both as a Lewis and a Brönsted base, being able to uptake protons[20]. So, pyridinic nitrogen can facilitate the reduction of $\left[\mathrm{Fe}(\mathrm{CN})_{6}\right]^{3-}$ to $\left[\mathrm{Fe}(\mathrm{CN})_{6}\right]^{4-}$. 

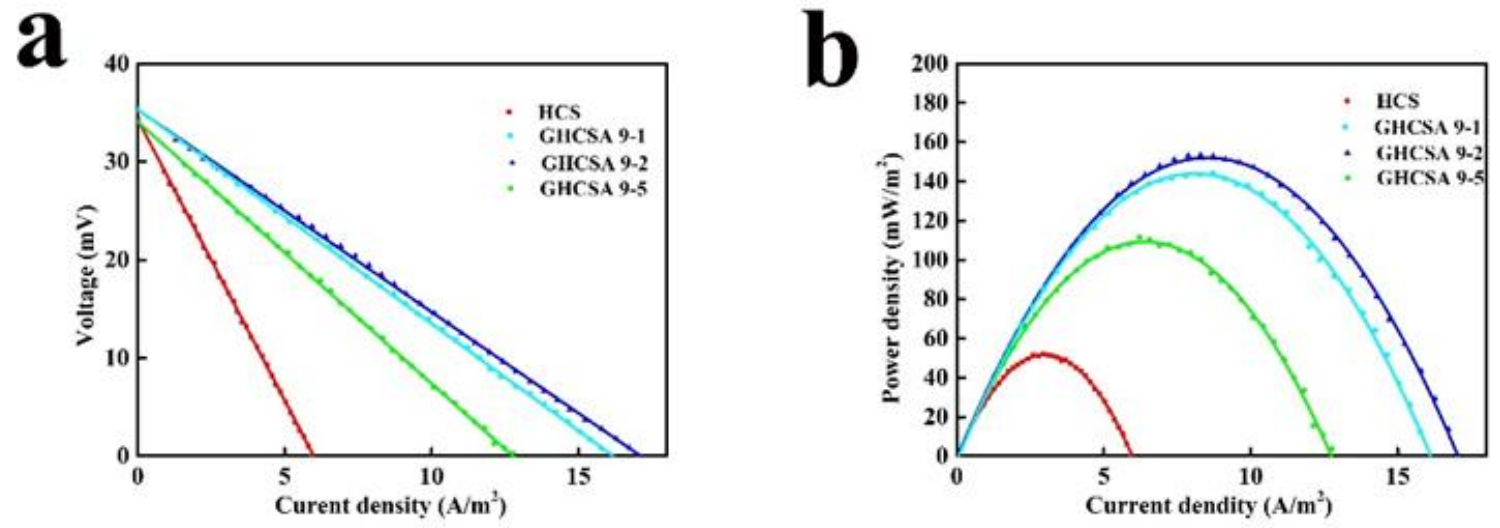

Figure S13. (a) cell voltage vs current density curves and (b) power density vs current density curves of the hollow carbon sphere aerogel electrodes with different hollow carbon spheres contents and hollow carbon spheres at $\Delta \mathrm{T} \approx 26{ }^{\circ} \mathrm{C}$.

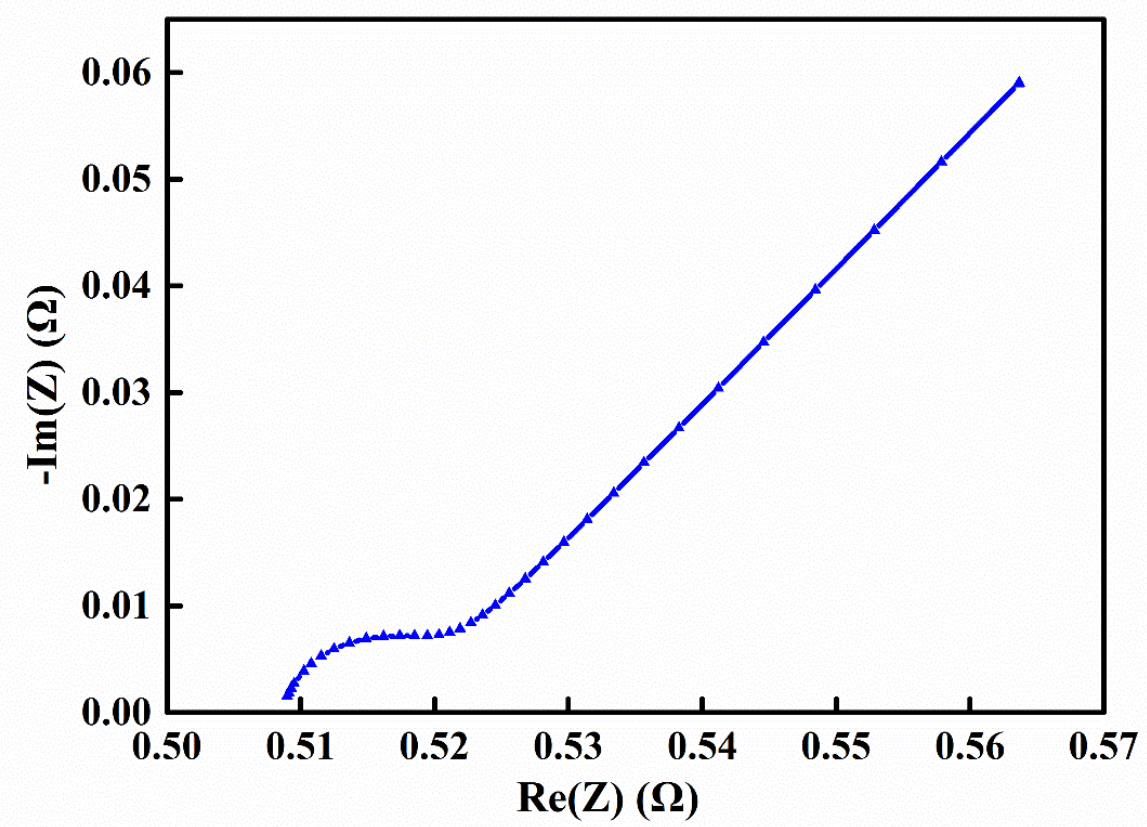

Figure S14. Nyquist plot generated using graphene-linked hollow carbon sphere aerogel electrode. Electrochemical impedance measurements were conducted in the frequency range between $10 \mathrm{kHz}$ and $50 \mathrm{mHz}$ using a commercial instrument (Dual Electrochemical workstation, ZIVE BP2). 0.4 
$\mathrm{M} \mathrm{K}_{3}\left[\mathrm{Fe}(\mathrm{CN})_{6}\right] / \mathrm{K}_{3}\left[\mathrm{Fe}(\mathrm{CN})_{6}\right]$ solution was used as electrolyte. Platinum and $\mathrm{Ag} / \mathrm{AgCl}$ electrodes were used as counter and reference electrodes for the electrochemical impedance measurements. The electrochemical impedance spectroscopy response of the graphene-linked hollow carbon sphere aerogel electrode exhibits a response that is controlled by a mixture of kinetics and diffusion [22]. The charge-transfer resistance, $R_{c t}$, may be estimated from the diameter of the semicircle in the Nyquist plot according to the Randles model[23]. The segment of the Nyquist plot approaching $45^{\circ}$ in the high-medium frequency range is indicative of the diffusion controlled impedance, called the Warburg impedance[24]. For the graphene-linked hollow carbon sphere aerogel electrode, $R_{c t}$ is found to be $10 \mathrm{~m} \Omega$. This may be attributed to the high conductivity of the aerogel. The solution resistance, $R_{S}$, was obtained by the intercept of the left side of the curve with the $\mathrm{X}$-axis [22]. The $\mathrm{R}_{\mathrm{S}}$ of the graphene-linked hollow carbon sphere aerogel was $510 \mathrm{~m} \Omega$. The high $\mathrm{R}_{\mathrm{S}}$ of the graphenelinked hollow carbon sphere aerogel sample may be caused by the defects introduced during synthesis, evidenced by the D-band in the Raman spectra. 
Tables

Table S1. Performance of the thermocell with different contents of hollow carbon spheres in aerogel

\begin{tabular}{lllll}
\hline Sample & HCS & GHCSA 9-1 & GHCSA 9-2 & GHCSA 9-5 \\
\hline $\mathrm{P}_{\max }\left(\mathrm{mW} / \mathrm{m}^{2}\right)$ & 51.5 & 141 & 151 & 109 \\
\hline$\eta_{\mathrm{r}}(\%)$ & 0.35 & 0.93 & 1.04 & 0.72 \\
\hline
\end{tabular}

Table S2. Comparison of the thermoelectric property of GHCS-aerogel based thermocell with other nanomaterials or nanocomposites based reported in the literature:

\begin{tabular}{|c|c|c|c|c|c|}
\hline Electrode & $\begin{array}{c}\text { Seebeck } \\
\text { coefficient } \\
(\mathrm{mV} / \mathrm{K})\end{array}$ & $\begin{array}{c}\mathrm{P}_{\max } \\
\text { (Specified) }\end{array}$ & $\begin{array}{c}\eta_{\mathrm{r}} \\
(\%)\end{array}$ & Remarks & Reference \\
\hline $\begin{array}{l}\text { GHCS- } \\
\text { aerogels }\end{array}$ & 1.43 & $1.05 \mathrm{~W} / \mathrm{m}^{2}$ & 1.4 & U-thermocell & Present work \\
\hline $\begin{array}{l}\text { graphite } \\
\text { sheet }\end{array}$ & 1.4 & $0.76 \mathrm{~W} / \mathrm{m}^{2}$ & $\begin{array}{l}\text { Not } \\
\text { mentioned }\end{array}$ & U-thermocell & $\begin{array}{l}\text { Nano Lett. 10(2010), } \\
838-846\end{array}$ \\
\hline SWCNTs & 1.43 & $0.09 \mathrm{~W} / \mathrm{m}^{2}$ & 0.275 & $\begin{array}{l}\text { Tube- } \\
\text { thermocell }\end{array}$ & $\begin{array}{l}\text { Adv. Funct. Mater. } \\
\text { 22(2012), 477-489 }\end{array}$ \\
\hline RGO films & 1.41 & $25.51 \mathrm{~W} / \mathrm{kg}$ & 0.012 & U-thermocell & $\begin{array}{l}\text { J. Therm Anal } \\
\text { Calorim, } 109 \text { (2012) } \\
\text { 1229-1235 }\end{array}$ \\
\hline $\begin{array}{l}\text { SWNT-rGO } \\
\text { composites }\end{array}$ & $\begin{array}{l}\text { Not } \\
\text { mentioned }\end{array}$ & $0.327 \mathrm{~W} / \mathrm{m}^{2}$ & 0.64 & $\begin{array}{l}\text { Tube- } \\
\text { thermocell }\end{array}$ & $\begin{array}{l}\text { Adv. Mater. 2013, } \\
25,6602-6606\end{array}$ \\
\hline $\begin{array}{l}\text { activated } \\
\text { carbon } \\
\text { textile } \\
\text { coated with } \\
\text { carbon } \\
\text { nanotubes }\end{array}$ & 1.4 & $0.46 \mathrm{~mW} / \mathrm{m}^{2}$ & $\begin{array}{l}\text { Not } \\
\text { mentioned }\end{array}$ & $\begin{array}{l}\text { Plate- } \\
\text { thermocell }\end{array}$ & $\begin{array}{l}\text { Nano Research. } \\
7(2014) \text { 443-452 }\end{array}$ \\
\hline $\begin{array}{l}\mathrm{Ag}-\mathrm{MgO}- \\
\text { CNTs } \\
\text { composites }\end{array}$ & 1.42 & $0.34 \mathrm{~W} / \mathrm{m}^{2}$ & 0.6 & U-thermocell & $\begin{array}{l}\text { RSC. Adv. } 5 \text { (2015) } \\
\text { 97982-97987. }\end{array}$ \\
\hline MWNT films & 1.42 & $0.82 \mathrm{~W} / \mathrm{m}^{2}$ & 0.9 & U-thermocell & $\begin{array}{l}\text { Nano-Micro Lett. } 8 \\
(2016) 240-246 .\end{array}$ \\
\hline $\begin{array}{l}\text { forest-drawn } \\
\text { CNT sheets }\end{array}$ & 1.4 & $0.04 \mathrm{~W} / \mathrm{m}^{2}$ & $\begin{array}{l}\text { Not } \\
\text { mentioned }\end{array}$ & $\begin{array}{l}\text { Tube- } \\
\text { thermocell }\end{array}$ & $\begin{array}{ll}\text { Nat. } & \text { commun., } \\
7(2016) & 10600 .\end{array}$ \\
\hline $\begin{array}{l}\text { MWNTs } \\
\text { foam }\end{array}$ & 1.43 & $1.2 \mathrm{~W} / \mathrm{m}^{2}$ & 0.4 & $\begin{array}{l}\text { Button- } \\
\text { thermocell }\end{array}$ & $\begin{array}{ll}\text { Adv. } & \text { Mater., } \\
29(2017), 1605652\end{array}$ \\
\hline
\end{tabular}

\section{References}

[1] B. Xu, S. F. Yue, Z. Y. Sui, X. T. Zhang, S. S. Hou, G. P. Cao, Y. S. Yang, Energy Environ. Sci. 4 (2011) 2826-2830.

[2] H. Huang, P. Chen, X. Zhang, Y. Lu, W. Zhan, Small 9 (2013) 1397-1404.

[3] L. Chen, B. Wei, X. T. Zhang, C. Li, Small 9 (2013) 2331-2340. 
[4] F. Xu, Z. Tang, S. Huang, L. Chen, Y. Liang, W. Mai, H. Zhong, R. Fu, D. Wu, Nat. Commun. $6(2015) 7221$.

[5] V. W. L. Lim, E. T. Kang, K. G. Neoh, Z. H. Ma, K. L. Tan, Appl. Surf. Sci. 181 (2001) 317326.

[6] J. S. Tang, X. B. Jing, B. C. Wang, F. S. Wang, Synth. Met. 24 (1988) 231-238.

[7] C. Zhou, J. Han, G. Song, R. Guo, J. Polym. Sci., Part A: Polym. Chem. 46 (2008) 3563-3572.

[8] D. C. Wu, F. Xu, B. Sun, R. W. Fu, H. K. He, K, Chem. Rev. 112 (2012) 3959-4015.

[9] F. Xu, Y. J. Lai, R. W. Fu, D. C. Wu, J. Mater. Chem. A. 1 (2013) 5001-5005.

[10] D. Chen, H. B. Feng, J. H. Li, Chem. Rev. 112 (2012) 6027-6053.

[11] D. R. Dreyer, S. Park, C. W. Bielawski, R. S. Ruoff, Chem. Soc. Rev. 39 (2010) 228-240.

[12] L. H. Tang, Y. Wang, Y. M. Li, H. B. Feng, J. Lu, J. H. Li, Adv. Funct. Mater. 19 (2009) 2782-2789.

[13] S. H. Park, S. M. Bak, K. H. Kim, J. P. Jegal, S. I. Lee, J. Lee, K. B. Kim, J. Mater. Chem. 21 (2011) 680-686.

[14] Z. S. Wu, W. C. Ren, L. B. Gao, J. P. Zhao, Z. P. Chen, B. L. Liu, D. M. Tang, B. Yu, C. B. Jiang, H. M. Cheng, ACS Nano 3 (2009) 411-417.

[15] R. Sun, H. Y. Chen, Q. W. Li, Q. J. Song, X. T. Zhang, Nanoscale 6 (2014) 12912-12920.

[16] J. T. Zhang, X. S. Zhao, J. Phys. Chem. C 116 (2012) 5420-5426.

[17] A. C. Ferrari, J. Robertson, Phys. Rev. B 61 (2000) 14095-14107.

[18] X. Zhang, Z. Sui, B. Xu, S. Yue, Y. Luo, W. Zhan, B. Liu, J. Mater. Chem. 21 (2011) 6494.

[19] K. S. W. Sing, D. H. Everett, R. A. W. Haul, L. Moscou, R. A. Pierotti, J. Rouquerol, T. Siemieniewska, Pure Appl. Chem. 57 (1985) 603-619

[20] A. Nieto-Marquez, D. Toledano, P. Sanchez, A. Romero and J. L. Valverde, J. Catal. 269.1 (2010) 242-251.

[21] Shimoyama, I.; Wu, G. H.; Sekiguchi, T.; Baba, Y., J. Electron Spectrosc. Relat. Phenom. 114 (2001) 841-848.

[22] M. S. Romano, N. Li, D. Antiohos, J. M. Razal, A. Nattestad, S. Beirne, S. L. Fang, Y. S.

Chen, R. Jalili, G. G. Wallace, R. Baughman, J. Chen, Adv. Mater. 25 (2013) 6602-6606.

[23] G. J. Brug, A. L. G. Vandeneeden, M. Sluytersrehbach, J. H. Sluyters, J. Electroanal. Chem. 176 (1984) 275-295.

[24] S. M. Park, J. S. Yoo, Anal. Chem. 75 (2003) 455A-461A. 


\section{Vitae:}

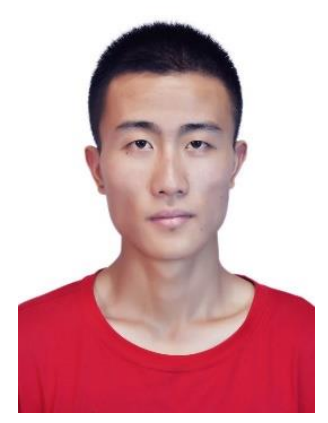

Dapeng Dong received his Bachelor's degree from North University of China in 2015. Now he is pursuing his M. Eng. under the supervision of Prof. Xuetong Zhang and Prof. Lifeng Yan at University of Science and Technology of China. His current research interest is mainly focused on the fabrication and electrochemical performance of the functionalized graphene aerogels.

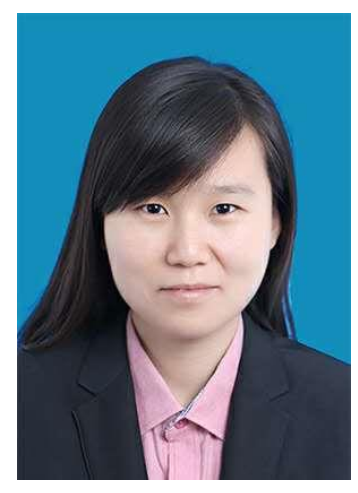

Haitao Guo received her Bachelor's degree from Henan University of Technology in 2012. She was postgraduate student at Beijing Institute of Technology where she received M. Sc. in 2016. Her research interest is focused on the controllable syntheses of conducting polymer based aerogels.

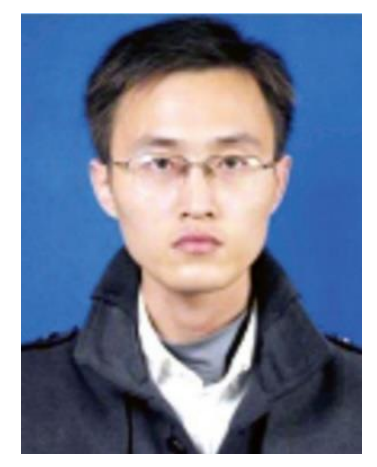


Guangyong Li received his M. Sc. in 2016 from College of Sciences, Shanghai University. Currently he is pursuing his Ph.D. degree under Prof. Xuetong Zhang's supervision in the School of Materials Science \& Engineering, Beijing Institute of Technology. His research interest is mainly focused on the controlled assembly and application of graphene aerogel.

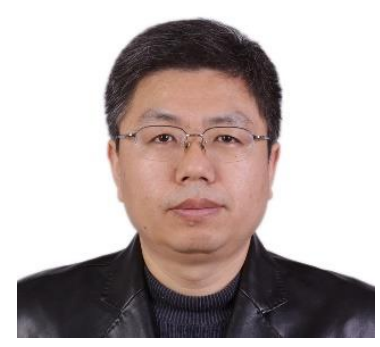

Prof. Lifeng Yan is a full professor of University of Science and Technology of China. He received his Ph.D. from University of Science and Technology of China in 2001. His research interests include green chemistry, polymer chemistry and physics. He has published more than 100 research papers.

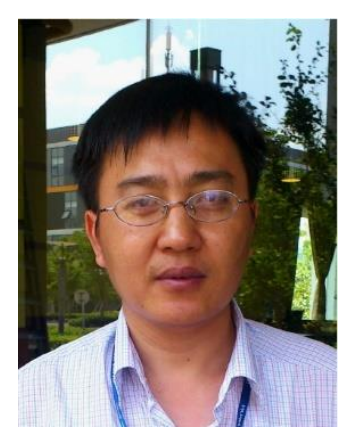

Prof. Xuetong Zhang received his Ph.D. from Beijing Institute of Technology in 2002 and conducted his postdoctoral work at Peking University, Brunel University and University of York. He joined the Suzhou Institute of Nano-Tech and Nano-Bionics, Chinese Academy of Sciences in 2013. His research interests are focused on design, synthesis and performance of various novel aerogels. He has published more than 70 research papers. 


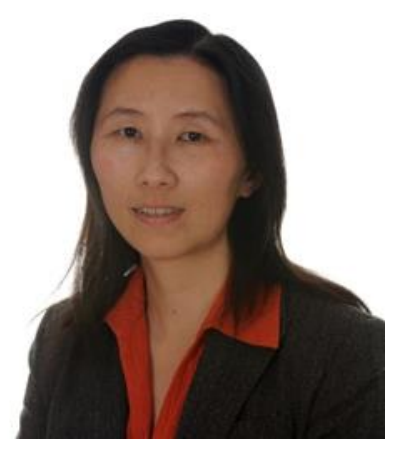

Dr Wenhui Song received her PhD from the University of Cambridge in UK, BEng and MEng from Beihang University in China. She is currently Reader and Director of the Centre for Biomaterials in the Division of Surgery and Interventional Science, University College London. Her research is primarily focused on three main areas: polymeric biomaterials, nanomaterials and nanocomposites for drug delivery and regenerative medicines, scaffolds for tissue regeneration and artificial organs, and implantable sensors and devices. Her laboratory is also developing novel bio-manufacturing technologies, such as engineered self-assembling, 3D bioprinting, and electrospinning for production of nanomedicines, scaffolds, implants, sensors and devices. 